\title{
Extracellular polysaccharides purified from Aureobasidium pullulans SM-2001 (Polycan) inhibit dexamethasone-induced muscle atrophy in mice
}

\author{
JONG-MIN LIM $^{1 *}$, YOUNG JOON LEE ${ }^{2 *}$, HYUNG-RAE CHO ${ }^{1}$, DONG-CHAN PARK ${ }^{1}$, \\ GO-WOON JUNG ${ }^{1}$, SAE KWANG KU ${ }^{3}$ and JAE-SUK CHOI ${ }^{4}$
}

\author{
${ }^{1}$ Glucan Corporation, \#305 Marine Bio-Industry Development Center, Busan 46048; \\ Departments of ${ }^{2}$ Preventive Medicine and ${ }^{3}$ Anatomy and Histology, College of Korean Medicine, Daegu Haany University, \\ Gyeongsan-si, Gyeongsangbuk-do 38610; ${ }^{4}$ Major in Food Biotechnology, Division of Bioindustry, \\ College of Medical and Life Sciences, Silla University, Busan 46958, Republic of Korea
}

Received May 10, 2017; Accepted October 31, 2017

DOI: $10.3892 /$ ijmm.2017.3251

\begin{abstract}
The present study assessed the beneficial skeletal muscle-preserving effects of extracellular polysaccharides from Aureobasidium pullulans SM-2001 (Polycan) (EAP) on dexamethasone (DEXA)-induced catabolic muscle atrophy in mice. To investigate whether EAP prevented catabolic DEXA-induced muscle atrophy, and to examine its mechanisms of action, EAP $(100,200$ and $400 \mathrm{mg} / \mathrm{kg}$ ) was administered orally, once a day for 24 days. EAP treatment was initiated 2 weeks prior to DEXA treatment (1 mg/kg, once a day for 10 days) in mice. Body weight alterations, serum biochemistry, calf thickness, calf muscle strength, gastrocnemius muscle thickness and weight, gastrocnemius muscle antioxidant defense parameters, gastrocnemius muscle mRNA expression, histology and histomorphometry were subsequently assessed. After 24 days, DEXA control mice exhibited muscle atrophy according to all criteria indices. However, these muscle atrophy symptoms were significantly inhibited by oral treatment with all three doses of EAP. Regarding possible mechanisms of action, EAP exhibited favorable ameliorating effects on DEXA-induced catabolic muscle atrophy via antioxidant and anti-inflammatory effects; these effects were mediated by modulation of
\end{abstract}

Correspondence to: Professor Jae-Suk Choi, Major in Food Biotechnology, Division of Bioindustry, College of Medical and Life Sciences, Silla University, 140 Baegyang-daero 700 Beon-gil, Sasang-gu, Busan 46958, Republic of Korea

E-mail: jsc1008@silla.ac.kr

Professor Sae Kwang Ku, Department of Anatomy and Histology, College of Korean Medicine, Daegu Haany University, 1 Hanuidae-ro, Gyeongsan-si, Gyeongsangbuk-do 38610, Republic of Korea

E-mail: gucci200@hanmail.net

*Contributed equally

Key words: dexamethasone, proteolysis, muscle atrophy, Aureobasidium pullulans, $\beta$-glucan the expression of genes involved in muscle protein synthesis (AKT serine/threonine kinase 1, phosphatidylinositol 3-kinase, adenosine A1 receptor and transient receptor potential cation channel subfamily V member 4) and degradation (atrogin-1, muscle RING-finger protein-1, myostatin and sirtuin 1). Therefore, these results indicated that EAP may be helpful in improving muscle atrophies of various etiologies. EAP at $400 \mathrm{mg} / \mathrm{kg}$ exhibited favorable muscle protective effects against DEXA-induced catabolic muscle atrophy, comparable with the effects of oxymetholone $(50 \mathrm{mg} / \mathrm{kg})$, which has been used to treat various muscle disorders.

\section{Introduction}

Aging is associated with a progressive reduction in muscle mass and strength $(1,2)$, which is known as sarcopenia. Sarcopenia is recognized as an important risk factor associated with disability and mortality (3). Daily life is largely affected by the loss of skeletal muscle mass, which subsequently leads to skeletal muscle atrophy (4). Muscle atrophy is mainly caused by musculoskeletal injury, denervation, ligament and joint immobilization, joint inflammation, joint injuries, prolonged bed rest, sepsis, aging, cancer and glucocorticoid treatment (5-7).

In research, various model organisms of skeletal muscle atrophy have been developed, via unloading $(8,9)$, immobilization (10), starvation (11), denervation (12) and administration of glucocorticoids (13). Among them, high doses of dexamethasone (DEXA) stimulate muscle proteolysis causing catabolic alterations in skeletal muscles $(14,15)$. The ubiquitin-proteasome and lysosomal pathways are predominantly responsible for activation of glucocorticoid-induced protein degradation (16). Proteins involved in these pathways include atrogin-1, muscle-specific E3-ligases, muscle RING-finger protein-1 (MuRF1), cathepsin L and lysosomal enzyme (17-19). Furthermore, upregulation of myostatin is an important negative regulator of skeletal muscle mass (20), which is associated with glucocorticoid-induced catabolic muscle atrophy (21). Muscle structure and mass are deter- 
mined by the equilibrium between protein synthesis and degradation, and various proteins are involved in disused muscle atrophy (9). The mRNA expression levels of these proteins can be readily detected using reverse transcription polymerase chain reaction (RT-PCR), and RT-quantitative (q) PCR has been used to determine the efficacy of animal models of disused muscle atrophy $(9,22)$. In addition, apoptosis $(23)$, muscle fiber loss and destruction of the muscle antioxidant defense system $(24,25)$ are involved in glucocorticoid-induced catabolic muscle atrophy (26). These findings suggest that glucocorticoid-induced muscle atrophy is a valuable and efficient animal model that may be used to identify agents that protect against abnormal catabolic muscle atrophy (26-29).

Oxymetholone (17 $\beta$-hydroxy-2-hydroxymethylidene-17 $\alpha$-methyl-3-androstanone) is an orally active $17 \alpha$-alkylated anabolic-androgenic steroid (30). It has a fully saturated cyclic hydrocarbon structure, which may limit the risk of hepatotoxicity (31). Oxymetholone exhibits higher anabolic activity and lower androgenic activity than methyltestosterone, testosterone and testosterone propionate (32). Oxymetholone has been approved by the US Food and Drug Administration for the treatment of anemia-associated problems that are caused by deficient red blood cell production (33). To date, oxymetholone has been used to treat various musculoskeletal disorders and as a reference drug for the production of muscle enhancers (26,33-35). However, it also exerts hepatotoxic effects $(36,37)$ and decreases anticoagulant tolerance (38).

Numerous polysaccharides are able to activate cellular components involved in host defense mechanisms (39). $\beta-1,3 / 1,6$-glucan is derived from yeast cell walls and modulates numerous in vivo and in vitro activities (40). It has previously been associated with antitumor effects (41), radioprotective actions (42), increased host resistance to bacterial, viral and parasitic infections (43), and adjuvant effects (44). Extracellular polysaccharides purified from Aureobasidium pullulans SM-2001 (Polycan) (EAP) contain 13\% $\beta$-1,3/1,6-glucan $(45,46)$ as a specific component, and have exhibited favorable antiosteoporotic activities (46), anti-inflammatory activities against xylene-induced acute (47) and formalin-induced chronic (48) inflammation, potent immunomodulatory activities in cyclophosphamide-induced immunosuppressed mice (45), nephroprotective effects (49), ameliorating effects on ovalbumin-induced asthma (50), antiosteoarthritic effects (51), and therapeutic effects against experimental periodontitis and associated alveolar bone losses (52), via powerful immunomodulatory, antioxidant and anti-inflammatory mechanisms.

The present study aimed to investigate whether administration of EAP prevented or improved glucocorticoid-induced catabolic muscle atrophy and to examine its possible mechanism(s) of action. EAP (100, 200 and $400 \mathrm{mg} / \mathrm{kg}$ ) was administered orally, once per day for 24 days; EAP treatment was initiated 2 weeks prior to DEXA treatment in mice. The results from the EAP-treated mice were then compared with those from mice treated with the $17 \alpha$-alkylated anabolic-androgenic steroid, oxymetholone, at an oral dose of $50 \mathrm{mg} / \mathrm{kg}(51,52)$.

\section{Materials and methods}

Test substances. Light brown EAP powder was supplied by Glucan Corporation (Busan, South Korea) and was stored at $4^{\circ} \mathrm{C}$. EAP consisted of $13 \% \beta-1,3 / 1,6$-glucan and $40 \% \beta$-glucans, as determined using previously described analytical methods $(45,46,53)$. Oxymetholone (50 mg tablet; Celltrion, Incheon, South Korea) was used as a reference drug; tablets were ground and were also stored at $4^{\circ} \mathrm{C}$ protected from light. Ground $50 \mathrm{mg}$ oxymetholone tablets were dissolved at a $15 \mathrm{mg} / \mathrm{ml}$ concentration $(5 \mathrm{mg} / \mathrm{ml}$ oxymetholone) in deionized distilled water. EAP was dissolved at $40 \mathrm{mg} / \mathrm{ml}$ in deionized distilled water.

Animals and experimental design. A total of 60 adult male SPF/ICR mice (6 weeks old), weighing 27-30 g were obtained from Orient Bio, Inc. (Seongnam, South Korea). After 10 days of acclimatization, the 48 mice that were well acclimatized in the laboratory environment ( 8 mice per group; a total of 6 groups) were used in the present study. The mice were maintained in polycarbonate cages $(n=4-5 \mathrm{mice} /$ cage) in a humidity (40-45\%)- and temperature $\left(20-25^{\circ} \mathrm{C}\right)$-controlled room under a 12-h light/dark cycle. Normal rodent pellets (cat. no. 38057; Purina Feed, Seongnam, South Korea) and water were provided ad libitum during acclimation.

Three doses of EAP (100, 200 and $400 \mathrm{mg} / \mathrm{kg}$ ) were administered orally in a volume of $10 \mathrm{ml} / \mathrm{kg}$, once a day for 24 days; EAP treatment was initiated 2 weeks prior to DEXA treatment. In addition, $50 \mathrm{mg} / \mathrm{kg}$ oxymetholone was administered orally, in a similar manner to EAP. EAP was dissolved at 10, 20 or $40 \mathrm{mg} / \mathrm{ml}$ in distilled water, and was administered orally in a volume of $10 \mathrm{ml} / \mathrm{kg}$ body weight using a zonde needle attached to a $1 \mathrm{ml}$ syringe. Ground $50 \mathrm{mg}$ oxymetholone tablets were also dissolved in distilled water at $15 \mathrm{mg} / \mathrm{ml}(5 \mathrm{mg} / \mathrm{ml}$ as oxymetholone) and administered orally at $10 \mathrm{ml} / \mathrm{kg}$, which was equivalent to $150 \mathrm{mg} / \mathrm{kg}$ (50 mg/kg as oxymetholone). The dosage of oxymetholone was selected based on previous efficacy tests in mice (26,33-35). Doses of 100, 200 and $400 \mathrm{mg} / \mathrm{kg}$ EAP were selected based on previously reported in vivo efficacy tests of EAP $(45,46)$. In the present study, catabolic muscle atrophy was initiated by subcutaneous treatment with $1 \mathrm{mg} / \mathrm{kg}$ DEXA, once a day for 10 days, according to previously reported methods $(16,26)$. Water-soluble DEXA (Sigma-Aldrich; Merck KGaA, Darmstadt, Germany) was dissolved in saline at $1.5 \mathrm{mg} / \mathrm{ml}(0.1 \mathrm{mg} / \mathrm{ml}$ DEXA) and was subcutaneously injected into the cervical dorsal region in a volume of $10 \mathrm{ml} / \mathrm{kg}$, equivalent to $15 \mathrm{mg} / \mathrm{kg}$ (1 mg/kg as DEXA itself). An equal volume of deionized distilled water, instead of oxymetholone or EAP, was orally administered in the DEXA control and intact vehicle groups, and an equal volume of saline, instead of DEXA, was injected subcutaneously into the intact vehicle control group. The present study was conducted in accordance with international regulations of the usage and welfare of laboratory animals, and was approved by the Institutional Animal Care and Use Committee, Daegu Haany University (Gyeongsan, South Korea; approval no. DHU2016-051, May 27, 2016).

Body weight measurements. Body weight (g) was measured 1 day prior to, the day of, and 1, 7, 14, 19, 23 and 24 days after treatment administration using an electronic balance (Precisa Gravimetrics AG, Dietikon, Switzerland). The gain in body weight during the 14 days of pretreatment, the 10 days of DEXA treatment and the total 24-day treatment periods was measured to decrease individual differences, according to equation 1 , where BW indicates body weight: 
During 14 days of pretreatment $=$ BW at 14 days after initial administration - BW at first administration (Eq. 1a).

During 10 days of DEXA treatment $=$ BW on the last day of DEXA treatment - BW on the first day of DEXA treatment ${ }^{\mathrm{a}}$ (Eq. 1b). ${ }^{\mathrm{a}} \mathrm{A}$ total of 2 weeks after pretreatment.

During total 24 days of treatment $=\mathrm{BW}$ at sacrifice $-\mathrm{BW}$ on the first day of pretreatment (Eq. 1c).

Calf and gastrocnemius muscle thickness measurements. The thickness of the left hind calf was measured 1 day prior to, the day of, and 1, 7, 14, 19, 23 and 24 days after treatment administration using electronic digital calipers (Mitutoyo, Tokyo, Japan), similar to previous studies $(26,35)$. Gastrocnemius muscle thickness in the left hind limb was measured following muscle exposure after sacrifice (all mice were sacrificed at the end of the 24-day period; liver, kidney, pancreas, calf muscle mass and gastrocnemius muscle tissues were collected following sacrifice), in order to decrease variability from the surrounding tissues. Gastrocnemius muscle thickness was measured according to the method used to measure calf thickness; alterations in calf thickness (mm) during 14 days of pretreatment, 10 days of DEXA treatment and the total 24-day treatment period were measured to reduce individual differences, according to equation 2, where CT indicates calf thickness:

During 14 days of pretreatment $=\mathrm{CT}$ at 14 days after initial administration $-\mathrm{CT}$ at first administration (Eq. 2a).

During 10 days of DEXA treatment $=\mathrm{CT}$ at the last day of DEXA treatment $-\mathrm{CT}$ at the first day DEXA treatment ${ }^{\mathrm{a}}$ (Eq. 2b). ${ }^{\mathrm{a}} \mathrm{A}$ total of 2 weeks after pretreatment.

After 24 days of treatment $=\mathrm{CT}$ at sacrifice $-\mathrm{CT}$ on the first day of pretreatment (Eq. 2c).

Calf muscle strength measurements. A total of $1 \mathrm{~h}$ after the last dose of oxymetholone, vehicle or EAP was administered (10 days after the initial DEXA treatment), the calf muscle strengths of individual mice were measured as tensile strengths using a computerized testing machine (SV-H1000, Japan Instrumentation System Co., Ltd., Tokyo, Japan) in Newtons (N) according to established methods $(26,35)$. Briefly, animals were restrained in the machine using two separate 1-0 silk suture ties on the chest and left ankle, and the peak tensile loads were documented as calf muscle strengths during knee angle reach of $0^{\circ}$ (10-20-mm distance).

Gastrocnemius muscle weight measurements. After gastrocnemius muscle thickness was measured following sacrifice, the gastrocnemius muscles were separated carefully from the tibia and fibula bones. The weights of individual gastrocnemius muscles were measured in $\mathrm{g}$ (absolute wet-weights) using an electronic balance, and to reduce the differences from individual body weights, relative weights ( $\%$ of body weights) were calculated according to body weight at sacrifice and absolute weight, following equation 3 .

Relative muscle mass (\% of body weight $)=\left[\frac{\text { absolute muscle mass }}{\text { body weight at sacrifice }}\right] \times 100$ (Eq. 3)
Serum biochemistry. To obtain sera for biochemical analysis, blood samples were collected on the day of sacrifice using a separation tube, and were then centrifuged at $600 \mathrm{x}$ g for $10 \mathrm{~min}$ at ambient temperature. Separated serum samples were stored at $-150^{\circ} \mathrm{C}$ in an ultra-deep freezer until further analysis. Serum creatine, creatine kinase (CK) and lactate dehydrogenase (LDH) levels were measured using an auto analyzer (Dri-Chem NX500i; FUJIFILM Medical Systems U.S.A., Inc., Stamford, CT, USA).

Antioxidant defense systems. Following muscle mass measurements, gastrocnemius muscles were separated and the malondialdehyde (MDA), glutathione (GSH) and reactive oxygen species (ROS) contents, and superoxide dismutase (SOD) and catalase (CAT) enzyme activities were assessed in individual muscles. Separated gastrocnemius muscles were weighed and homogenized in ice-cold $0.01 \mathrm{M}$ Tris- $\mathrm{HCl}$ ( $\mathrm{pH} 7.4)$, after which they were centrifuged at $12,000 \mathrm{x}$ g for $15 \mathrm{~min}$ at ambient temperature, as described previously (54). Muscle tissue homogenates were stored at $-150^{\circ} \mathrm{C}$ in an ultra-deep freezer until analysis. The degree of gastrocnemius muscle lipid peroxidation was measured by assessing MDA values using the thiobarbituric acid test at $525 \mathrm{~nm}$ using a UV/vis spectrometer (Optizen POP; Mecasys Co., Ltd., Daejeon, South Korea) (55). The total protein contents were measured using the Lowry method (56), whereas bovine serum albumin (Invitrogen; Thermo Fisher Scientific, Inc., Waltham, MA, USA) was used as a standard. ROS level analyses were performed using 2',7'-dichlorofluorescein diacetate fluorescent dye as a probe and fluorescence density was measured at $490 / 520 \mathrm{~nm}$ according to the manufacturer's protocol (Cellular Reactive Oxygen Species Detection assay kit; ab113851; Abcam, Cambridge, MA, USA); the measured optical density values were corrected to the protein contents of samples and were expressed as RFU/ $\mu \mathrm{g}^{-1}$ protein (57). In addition, prepared homogenates were mixed with $0.1 \mathrm{ml} \mathrm{25 \%}$ trichloroacetic acid (EMD Millipore, Billerica, MA, USA) and were then centrifuged at $800 \mathrm{x} \mathrm{g}$ for $40 \mathrm{~min}$ at $4^{\circ} \mathrm{C}$. GSH contents were measured at $412 \mathrm{~nm}$ using 2-nitrobenzoic acid (Sigma-Aldrich; Merck KGaA), and were expressed as $\mathrm{mg} / \mathrm{g}^{-1}$ tissue (58). $\mathrm{H}_{2} \mathrm{O}_{2}$ decomposition in the presence of CAT was estimated at $240 \mathrm{~nm}$ (59). CAT activity was defined as the amount of enzyme required to decompose $1 \mathrm{nM}$ $\mathrm{H}_{2} \mathrm{O}_{2}$ per min, at $25^{\circ} \mathrm{C}$ and $\mathrm{pH} 7.8$, and the results are expressed as $\mathrm{U} / \mathrm{mg}^{-1}$ protein. Furthermore, SOD activity was measured at $560 \mathrm{~nm}$ according to a protocol previously described by Sun et al (60), and was expressed as $\mathrm{U} / \mathrm{mg}^{-1}$ protein. One unit of SOD enzymatic activity is equal to the amount of enzyme that diminishes the initial absorbance of nitroblue tetrazolium by $50 \%$ during $1 \mathrm{~min}$.

$R T$ - $q P C R$. Total RNA was extracted from gastrocnemius muscles using TRIzol reagent (Invitrogen; Thermo Fisher Scientific, Inc.), according to previous studies $(9,26,35,61)$. The RNA concentration and quality were determined using a CFX96 ${ }^{\mathrm{TM}}$ Real-Time PCR Detection system using iTaq ${ }^{\mathrm{TM}}$ SYBR-Green (both from Bio-Rad Laboratories, Inc., Hercules, CA, USA). The samples were treated with recombinant DNase I (DNA-free DNA removal kit; Ambion, Austin, TX, USA) to remove possible DNA contamination. RNA was reverse-transcribed using the High-Capacity cDNA Reverse Transcription kit (Applied Biosystems; Thermo Fisher Scientific, Inc.) according to the manufacturer's protocol. The PCR cycling 
Table I. Oligonucleotides for quantitative polymerase chain reaction used in the present study.

\begin{tabular}{|c|c|c|c|}
\hline Target & Sequences $\left(5^{\prime}-3^{\prime}\right)$ & Size (bp) & Gene ID \\
\hline Atrogin-1 & $\begin{array}{l}\text { F: CAGCTTCGTGAGCGACCTC } \\
\text { R: GGCAGTCGAGAAGTCCAGTC }\end{array}$ & 244 & 67731 \\
\hline MuRF 1 & $\begin{array}{l}\text { F: GACAGTCGCATTTCAAAGCA } \\
\text { R: GCCTAGCACTGACCTGGAAG }\end{array}$ & 194 & 433766 \\
\hline PI3K p85 $\alpha$ & $\begin{array}{l}\text { F: GCCAGTGGTCATTTGTGTTG } \\
\text { R: ACACAACCAGGGAAGTCCAG }\end{array}$ & 236 & 18708 \\
\hline Akt1 & $\begin{array}{l}\text { F: ATGAACGACGTAGCCATTGTG } \\
\text { R: TTGTAGCCAATAAAGGTGCCAT }\end{array}$ & 116 & 11651 \\
\hline Adenosine A1R & $\begin{array}{l}\text { F: TGTTCCCAGGGCCTTTCAC } \\
\text { R: TAATGGACTGAGACTAGCTTGACTGGTA }\end{array}$ & 155 & 11539 \\
\hline TRPV4 & $\begin{array}{l}\text { F: CAGGACCTCTGGAAGAGTGC } \\
\text { R: AAGAGCTAGCCTGGACACCA }\end{array}$ & 165 & 63873 \\
\hline Myostatin & $\begin{array}{l}\text { F: CCTCCACTCCGGGAACTGA } \\
\text { R: AAGAGCCATCACTGCTGTCATC }\end{array}$ & 185 & 17700 \\
\hline SIRT1 & $\begin{array}{l}\text { F: TTCACATTGCATGTGTGTGG } \\
\text { R: TGAGGCCCAGTGCTCTAACT }\end{array}$ & 175 & 93759 \\
\hline $18 \mathrm{~S}$ ribosomal RNA & $\begin{array}{l}\text { F: AGCCTGAGAAACGGCTACC } \\
\text { R: TCCCAAGATCCAACTACGAG }\end{array}$ & 252 & 19791 \\
\hline
\end{tabular}

A1R, A1 receptor; Akt1, AKT serine/threonine kinase 1; F, forward; MuRF1, muscle RING-finger protein-1; PI3K, phosphatidylinositol 3-kinase; R, reverse; SIRT1, sirtuin 1; TRPV4, transient receptor potential cation cannel subfamily V member 4.

conditions were as follows: Initial pre-denaturation of $95^{\circ} \mathrm{C}$ for $1 \mathrm{~min}$, denaturation for $15 \mathrm{sec}$, annealing of $55-65^{\circ} \mathrm{C}$ for $20 \mathrm{sec}$ and extension of $72^{\circ} \mathrm{C}$ for $30 \mathrm{sec}$. A total of 50 cycles were performed. $18 \mathrm{~S}$ ribosomal RNA was used as an internal control. PCR primer sequences are listed in Table I. For quantitative analysis, the intact control muscle tissue was used as the control, and the relative expression of Atrogin-1, MuRF 1, PI3K p85 $\alpha$, Akt1, Adenosine A1R, TRPV4, Myostatin and SIRT1 was calculated using the $2^{-\Delta \Delta C t}$ method (62).

Histopathology. Samples from gastrocnemius muscles were separated and fixed in $10 \%$ neutral buffered formalin, embedded in paraffin wax, sectioned (3-4 $\mu \mathrm{m})$, and stained with Sirius red for collagen fibers or hematoxylin and eosin for general histopathology $(63,64)$. Histopathological profiles were observed under a light microscope (Eclipse 80i; Nikon Corporation, Tokyo, Japan). Mean muscle fiber diameters $\left(\mu \mathrm{m} /\right.$ fiber) and collagen fiber-occupied regions $\left(\% / \mathrm{mm}^{2}\right)$ in muscle bundles were calculated using an automated image analyzer (iSolution FL, version 9.1; Brooke Anco Corporation, Cicero, NY, USA) in gastrocnemius muscle samples, according to previous studies $(9,15,21,26,35,63)$ with some modifications.

Immunohistochemistry. Following deparaffinization of gastrocnemius muscle histological sections, citrate buffer antigen retrieval was conducted as previously described $(26,35,65)$. Briefly, a staining dish containing $10 \mathrm{mM}$ citrate buffer ( $\mathrm{pH}$ 6.0) was preheated at $95-100^{\circ} \mathrm{C}$ in a water bath. Slides were immersed in the staining dish and incubated for $20 \mathrm{~min}$ prior to turning off the water bath. The staining dish was placed at room temperature and the slides were allowed to cool for $20 \mathrm{~min}$. Subsequently, sections were immunostained using the avidin-biotin complex (ABC) method, to detect caspase-3, poly (ADP-ribose) polymerase (PARP), nitrotyrosine, 4-hydroxynonenal (4-HNE), inducible nitric oxide synthase (iNOS) and myostatin expression (Table II) according to previous studies $(26,35)$. Briefly, endogenous peroxidase activity was blocked by incubation in methanol and $0.3 \% \mathrm{H}_{2} \mathrm{O}_{2}$ for $30 \mathrm{~min}$ at ambient temperature, and non-specific binding was blocked with normal horse serum blocking solution (1:100; Vector Laboratories, Inc., Burlingame, CA, USA) for $1 \mathrm{~h}$ at ambient temperature in a humidified chamber. Slides were incubated with primary antibodies (Table II) overnight at $4^{\circ} \mathrm{C}$ in a humidified chamber, and were then incubated with biotinylated universal secondary antibody [1:50; Vectastain Elite ABC kit (PK-6200); Vector Laboratories, Inc.] and ABC reagents (1:50; Vectastain Elite ABC kit, Vector Laboratories, Inc.) for $1 \mathrm{~h}$ at room temperature in a humidified chamber. Finally, sections were treated with a peroxidase substrate kit (Vector Laboratories, Inc.) for $3 \mathrm{~min}$ at room temperature. All of the sections were rinsed in 0.01 M PBS three times between steps. Cells or muscle fibers that exhibited $>20 \%$ immunoreactivity with each antibody were considered positive, and the mean numbers of caspase-3, PARP, nitrotyrosine, 4-HNE, iNOS and myostatin-immunoreactive fibers, as dispersed in $1 \mathrm{~mm}^{2}$ of muscle bundles, were counted using an image analysis process described by Kim et al $(26,35)$ with 
Table II. Primary antibodies and detection kits used in the present study.

\begin{tabular}{|c|c|c|c|}
\hline Antibodies or detection kits & Cat. no. & Source & Dilution \\
\hline \multicolumn{4}{|l|}{ Primary antibodies ${ }^{\mathrm{a}}$} \\
\hline Anti-cleaved caspase-3 (Asp175) polyclonal antibody & 9661 & $\begin{array}{l}\text { Cell Signaling Technology Inc. } \\
\text { (Danvers, MA, USA) }\end{array}$ & $1: 400$ \\
\hline Anti-cleaved PARP (Asp214) specific antibody & 9545 & Cell Signaling Technology Inc. & $1: 100$ \\
\hline Anti-4-hydroxynonenal polyclonal antibody & Ab46545 & Abcam (Cambridge, UK) & $1: 100$ \\
\hline Anti-nitrotyrosine polyclonal antibody & $06-284$ & EMD Millipore (Billerica, CA, USA) & $1: 200$ \\
\hline Anti-nitric oxide synthase $2(\mathrm{~N}-20)$ polyclonal antibody & sc-651 & $\begin{array}{l}\text { Santa Cruz Biotechnology, Inc. } \\
\text { (Dallas, TX, USA) }\end{array}$ & $1: 100$ \\
\hline Anti-GDF8/Myoststin antibody & Ab71808 & Abcam & $1: 50$ \\
\hline \multicolumn{4}{|l|}{ Detection kits } \\
\hline Vectastain Elite ABC kit & PK-6200 & $\begin{array}{l}\text { Vector Laboratories, Inc. (Burlingame, CA, } \\
\text { USA) }\end{array}$ & $1: 50$ \\
\hline Peroxidase substrate kit & SK-4100 & Vector Laboratories, Inc. & $1: 50$ \\
\hline
\end{tabular}

Table III. Alterations in body weight in mice with DEXA-induced muscle atrophy.

\begin{tabular}{|c|c|c|c|}
\hline \multirow[b]{2}{*}{ Group } & \multicolumn{3}{|c|}{ Weight gain $(\mathrm{g})$} \\
\hline & $\begin{array}{l}14 \text { days of test material } \\
\text { pretreatment }\end{array}$ & $\begin{array}{l}10 \text { days of DEXA } \\
\text { treatment }\end{array}$ & Total 24 days of treatment \\
\hline \multicolumn{4}{|l|}{ Controls } \\
\hline Intact & $5.74 \pm 0.63$ & $1.30 \pm 0.34$ & $3.23 \pm 0.96$ \\
\hline DEXA & $5.63 \pm 0.49$ & $-5.50 \pm 0.81^{\mathrm{a}}$ & $-4.00 \pm 0.63^{b}$ \\
\hline \multicolumn{4}{|l|}{ Reference } \\
\hline Oxymetholone & $5.43 \pm 0.56$ & $-1.19 \pm 0.47^{\mathrm{a}, \mathrm{c}}$ & $0.20 \pm 0.66^{\mathrm{b}, \mathrm{d}}$ \\
\hline \multicolumn{4}{|l|}{ EAP-treated } \\
\hline $400 \mathrm{mg} / \mathrm{kg}$ & $5.68 \pm 0.58$ & $-1.49 \pm 0.73^{\mathrm{a}, \mathrm{c}}$ & $0.34 \pm 1.14^{\mathrm{b}, \mathrm{d}}$ \\
\hline $200 \mathrm{mg} / \mathrm{kg}$ & $5.71 \pm 0.41$ & $-2.58 \pm 0.52^{\mathrm{a}, \mathrm{c}}$ & $-0.73 \pm 0.55^{\mathrm{b}, \mathrm{d}}$ \\
\hline $100 \mathrm{mg} / \mathrm{kg}$ & $5.61 \pm 0.62$ & $-3.24 \pm 0.95^{\mathrm{a}, \mathrm{c}}$ & $-1.44 \pm 0.81^{\mathrm{b}, \mathrm{d}}$ \\
\hline
\end{tabular}

Values are expressed as the mean \pm standard deviation of 8 mice. Oxymetholone was orally administered at $50 \mathrm{mg} / \mathrm{kg}$, dissolved in distilled water. ${ }^{\mathrm{P}} \mathrm{P}<0.01$ compared with the intact control group, as determined by $\mathrm{MW}$ test. ${ }^{\mathrm{b}} \mathrm{P}<0.01$ compared with the intact control group, as determined by LSD test. ${ }^{\mathrm{C}}<<0.01$ compared with the DEXA control group, as determined by MW test. ${ }^{\mathrm{P}} \mathrm{P}<0.01$ compared with the DEXA control group, as determined by LSD test. DEXA, dexamethasone; EAP, extracellular polysaccharides purified from Aureobasidium pullulans SM-2001; LSD, least-significant difference; MW, Mann Whitney U.

some modifications. The histopathologist was blinded to the group distribution when performing the analysis.

Statistical analysis. All numerical values are expressed as the means \pm SD of 8 mice. Multiple comparison tests for different dose groups were conducted. Variance homogeneity was examined using the Levene test (66). If the Levene test indicated no significant deviation from variance homogeneity, data were analyzed by one-way analysis of variance followed by least-significant differences multi-comparison test to determine which pairs of group comparisons were significantly different. In cases where significant deviations from variance homogeneity were observed with the Levene test, the non-parametric Kruskal-Wallis H-test was used. When a significant difference was observed with the Kruskal-Wallis $\mathrm{H}$ test, the Mann-Whitney U test was conducted to determine the specific pairs of group comparisons that were significantly different. Statistical analyses were conducted using SPSS 14K for Windows software (SPSS Inc., Chicago, IL, USA) (67). Statistical significances were set at $\mathrm{P}<0.01$ and $\mathrm{P}<0.05$. Percent changes between intact vehicle and DEXA control groups were calculated to assess the severities of catabolic muscle atrophy 
Table IV. Alterations in calf thickness in mice with DEXA-induced muscle atrophy.

Calf thickness alterations (mm)

\begin{tabular}{|c|c|c|c|}
\hline Group & $\begin{array}{l}14 \text { days of test material } \\
\text { pretreatment }\end{array}$ & $\begin{array}{l}10 \text { days of DEXA } \\
\text { treatment }\end{array}$ & Total 24 days of treat \\
\hline \multicolumn{4}{|l|}{ Controls } \\
\hline Intact & $0.23 \pm 0.04$ & $0.09 \pm 0.06$ & $0.32 \pm 0.06$ \\
\hline DEXA & $0.23 \pm 0.04$ & $-0.91 \pm 0.04^{\mathrm{a}}$ & $-0.68 \pm 0.05^{\mathrm{a}}$ \\
\hline \multicolumn{4}{|l|}{ Reference } \\
\hline Oxymetholone & $0.27 \pm 0.05$ & $-0.34 \pm 0.04^{\mathrm{a}, \mathrm{b}}$ & $-0.07 \pm 0.04^{\mathrm{a}, \mathrm{b}}$ \\
\hline \multicolumn{4}{|l|}{ EAP-treated } \\
\hline $400 \mathrm{mg} / \mathrm{kg}$ & $0.24 \pm 0.05$ & $-0.33 \pm 0.04^{\mathrm{a}, \mathrm{b}}$ & $-0.09 \pm 0.04^{\mathrm{a}, \mathrm{b}}$ \\
\hline $200 \mathrm{mg} / \mathrm{kg}$ & $0.25 \pm 0.03$ & $-0.52 \pm 0.10^{\mathrm{a}, \mathrm{b}}$ & $-0.27 \pm 0.09^{\mathrm{a}, \mathrm{b}}$ \\
\hline $100 \mathrm{mg} / \mathrm{kg}$ & $0.24 \pm 0.03$ & $-0.62 \pm 0.04^{\mathrm{a}, \mathrm{b}}$ & $-0.39 \pm 0.05^{\mathrm{a}, \mathrm{b}}$ \\
\hline
\end{tabular}

Values are expressed as the mean \pm standard deviation of 8 mice. Oxymetholone was orally administered at $50 \mathrm{mg} / \mathrm{kg}$, dissolved in distilled water. ${ }^{a} \mathrm{P}<0.01$ compared with the intact control group, as determined by LSD test. ${ }^{\mathrm{b}} \mathrm{P}<0.01$ compared with the DEXA control group, as determined by LSD test. DEXA, dexamethasone; EAP, extracellular polysaccharides purified from Aureobasidium pullulans SM-2001; LSD, least-significant difference.

induced, and the percent changes between the DEXA control and test material-treated mice were calculated, in order to understand the efficacy of the test substances according to the following equations 4 and 5 :

Percentage change compared to the intact vehicle control group $(\%)=$

$\left[\frac{\text { Data of DEXA control - Data of intact vehicle control }}{\text { Data of intact vehicle control }}\right] \times 100$ (Eq. 4).

Percentage change compared to the DEXA control group $(\%)=$

$\left[\frac{\text { Data of test material treated mice - Data of DEXA control }}{\text { Data of DEXA control }}\right] \times 100$ (Eq. 5).

\section{Results}

Alterations in body weight. Significant decreases $(\mathrm{P}<0.01)$ in body weight were demonstrated in the DEXA control mice compared with in the intact control mice from 5 days after initial DEXA treatment to sacrifice. Accordingly, body weight during the 10 days of DEXA treatment, and after the total 24-day experimental period, was significantly decreased $(\mathrm{P}<0.01)$ in the DEXA control mice compared with in the intact vehicle control group. However, these decreases in body weight were significantly inhibited $(\mathrm{P}<0.01)$ by treatment with oxymetholone and all three doses of EAP (100, 200 and $400 \mathrm{mg} / \mathrm{kg}$ ) from 5 days after initial DEXA treatment to sacrifice. In addition, body weight after 10 days of DEXA treatment, and after the total 24-day experimental period, was significantly increased $(\mathrm{P}<0.01)$ in the oxymetholone- and EAP-treated mice compared with in the DEXA control group. Anyway, no test material treatment-related alterations in body weight were detected compared with intact vehicle or DEXA control mice in this experiment. Treatment with EAP (100, 200 and $400 \mathrm{mg} / \mathrm{kg})$ exhibited

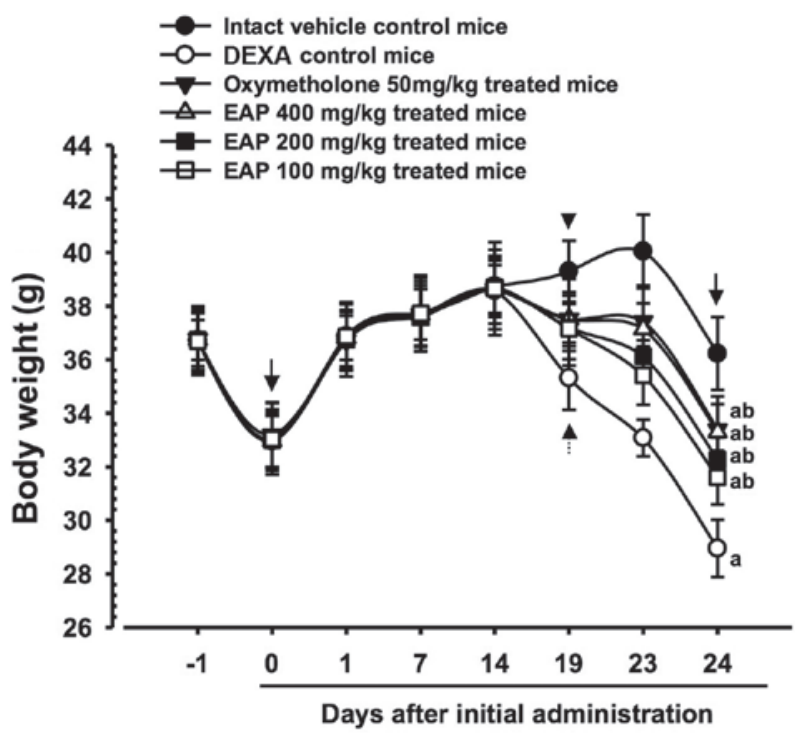

Figure 1. Body weight alterations in mice with DEXA-induced muscle atrophy. Significant decreases in body weight were detected in the DEXA control mice compared with in the intact control mice from 5 days after initial DEXA treatment, 19 days after initial administration (dotted arrow). However, these decreases in body weight were significantly inhibited by treatment with oxymetholone and all three doses of EAP (400, 200 and $100 \mathrm{mg} / \mathrm{kg}$ ), from 5 days after initial DEXA treatment (arrowhead) to sacrifice. EAP 400, 200 and $100 \mathrm{mg} / \mathrm{kg}$ exhibited clear dose-dependent inhibitory effects on DEXA-induced decreases in body weight, particularly EAP $400 \mathrm{mg} / \mathrm{kg}$, which exerted comparable effects to oxymetholone $(50 \mathrm{mg} / \mathrm{kg})$. No test material treatment-associated body weight alterations were detected compared with in the intact vehicle and DEXA control mice during the 14-day pretreatment period. Data are presented as the mean \pm standard deviation of 8 mice. Day -1 and 24 indicates 1 day prior to initial administration of test materials and the day of sacrifice, respectively. Day 0 indicates initiation of test material administration, at 2 weeks prior to initial DEXA treatment. All animals were fasted overnight prior to initial administration of test materials and sacrifice (arrows). ${ }^{a} \mathrm{P}<0.01$ compared with the intact control group, as determined by LSD test. ${ }^{b} \mathrm{P}<0.01$ compared with the DEXA control group, as determined by LSD test. DEXA, dexamethasone; EAP, extracellular polysaccharides purified from Aureobasidium pullulans SM-2001; LSD, least-significant difference. Results were significant at 24 days 


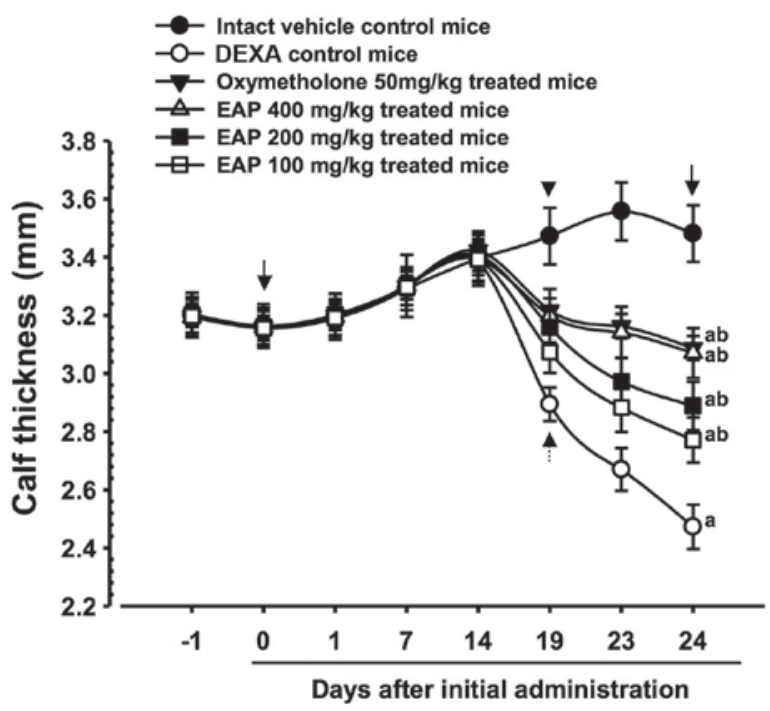

Figure 2. Calf thickness alterations in mice with DEXA-induced muscle atrophy. Significant decreases in calf thickness were revealed in the DEXA control mice compared with in the intact control mice from 19 days after the initial test substance administration to the day of sacrifice (dotted arrow). However, these decreases in calf thicknes were significantly and dose-dependently inhibited by treatment with all three doses of EAP $(400,200$ and $100 \mathrm{mg} / \mathrm{kg}$ ) from 5 days after the intial DEXA treatment (arrowhead). In addition, $50 \mathrm{mg} / \mathrm{kg}$ oxymetholone-treated mice also exhibited significant increases in calf thickness from 5 days after the intial DEXA treatment compared with in the DEXA control mice (arrowhead). EAP (400 mg/kg) exhibited favorable inhibitory activities on DEXA-induced decreases in calf thickness, as comparable to those of oxymetholone $(50 \mathrm{mg} / \mathrm{kg})$. Data are presented as the mean \pm standard deviation of 8 mice. Day -1 and 24 indicates 1 day prior to initial administration of test materials and the day of sacrifice, respectively. Day 0 indicates initiation of test material administration, at 2 weeks prior to initial DEXA treatment. All animals were fasted overnight prior to initial administration of test materials and sacrifice (arrows). ${ }^{\mathrm{a}} \mathrm{P}<0.01$ compared with the intact control group, as determined by LSD test. ${ }^{b} \mathrm{P}<0.01$ compared with the DEXA control group, as determined by LSD test. DEXA, dexamethasone; EAP, extracellular polysaccharides purified from Aureobasidium pullulans SM-2001; LSD, least-significant difference. Results were significant at 24 days

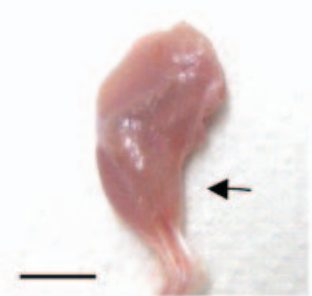

Intact control

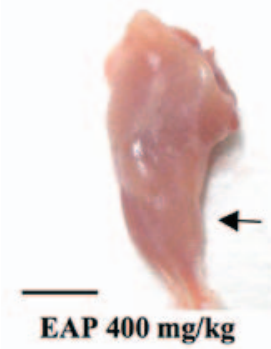

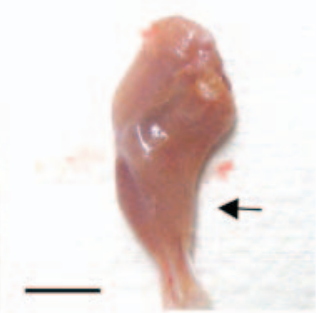

DEXA control

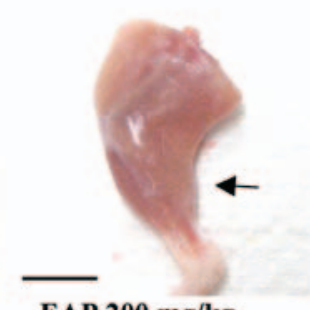

EAP $200 \mathrm{mg} / \mathrm{kg}$

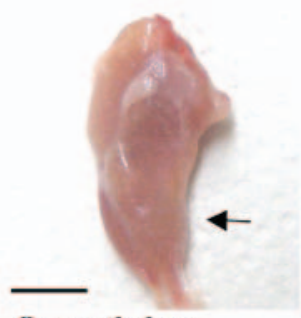

Oxymetholone

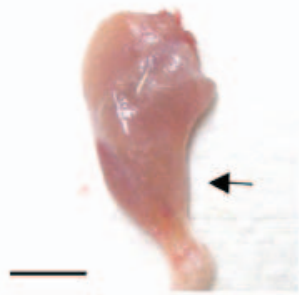

EAP $100 \mathrm{mg} / \mathrm{kg}$

Figure 3. Alterations in calf muscle mass in mice with DEXA-induced muscle atrophy. Marked decreases in calf muscle mass following muscle exposure (arrows) were detected in the DEXA control mice compared with in the intact vehicle control mice. However, marked increases in calf muscle mass were detected in the oxymetholone- and EAP-treated mice compared with in the DEXA control group. EAP (400, $200 \mathrm{and} 100 \mathrm{mg} / \mathrm{kg}$ ) exhibited obvious dose-dependent inhibitory effects on DEXA-induced decreases in gastrocnemius muscle mass; in particular, $400 \mathrm{mg} / \mathrm{kg}$ EAP exhibited favorable inhibitory activities on decreases in gastrocnemius muscle mass, which were comparable with those of $50 \mathrm{mg} / \mathrm{kg}$ oxymetholone. DEXA, dexamethasone; EAP, extracellular polysaccharides purified from Aureobasidium pullulans SM-2001. Scale bars=9 mm.

dose-dependent inhibitory effects on DEXA-induced decreases in body weight, in particular $400 \mathrm{mg} / \mathrm{kg}$ EAP exhibited favorable inhibitory activities on DEXA-induced decreases in body weight, which were comparable with the effects of $50 \mathrm{mg} / \mathrm{kg}$ oxymetholone (Table III and Fig. 1).

Effects on calf thickness. Significant decreases $(\mathrm{P}<0.01)$ in calf thickness were demonstrated in the DEXA control mice compared with in the intact control mice from 19 days after initial administration of the test substances to the day of sacrifice. Accordingly, calf thickness alterations after 10 days of DEXA treatment, and after the total 24-day test substance administration period, were also significantly decreased $(\mathrm{P}<0.01)$ in the DEXA control mice compared with in the intact vehicle controls. However, 5 days after the initial DEXA treatment, these decreases in calf thickness were significantly inhibited $(\mathrm{P}<0.01)$ by treatment with the three doses of EAP, and calf thickness during the 10 days of DEXA treatment, and the total 24-day test substance administration period, were also significantly increased $(\mathrm{P}<0.01)$ in these groups compared with in the DEXA control group. Furthermore, $50 \mathrm{mg} / \mathrm{kg}$ oxymetholone-treated mice also exhibited significant increases $(\mathrm{P}<0.01)$ in calf thickness from 5 days after the initial DEXA treatment, and also exhibited significant increases $(\mathrm{P}<0.01)$ in calf thickness during the 10 days of DEXA treatment and the total 24-day test substance administration period. A dose of $400 \mathrm{mg} / \mathrm{kg}$ EAP exhibited favorable inhibitory activities on DEXA-induced decreases in calf thickness, which were comparable with the effects of $50 \mathrm{mg} / \mathrm{kg}$ oxymetholone (Table IV and Fig. 2). 


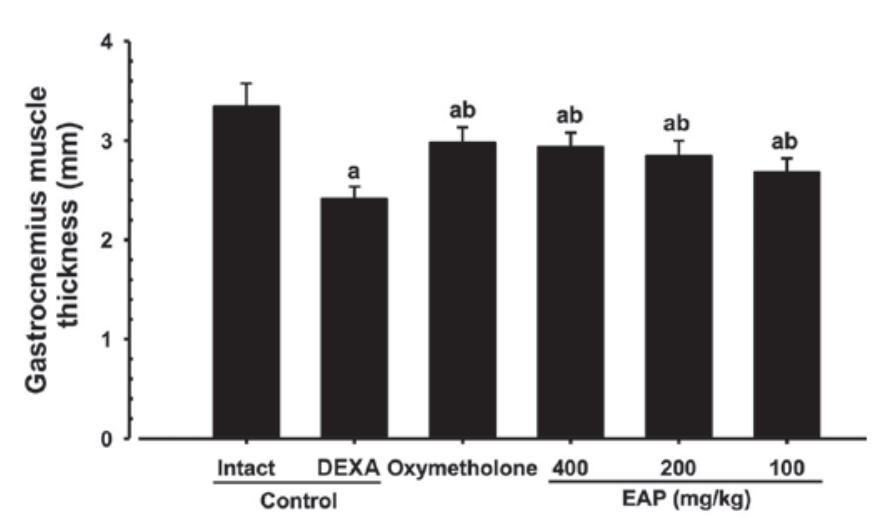

Figure 4. Alterations in gastrocnemius muscle thickness following muscle exposure in mice with DEXA-induced muscle atrophy. Significant decreases in gastrocnemius muscle thickness following muscular exposure were detected in the DEXA control mice compared with in the intact vehicle control mice. However, significant increases in gastrocnemius muscle thickness were observed in oxymetholone- and EAP-treated mice compared with in the DEXA control group. EAP (400, 200 and $100 \mathrm{mg} / \mathrm{kg})$ exhibited marked dose-dependent inhibitory effects on DEXA-induced decreases in gastrocnemius muscle thickness; in particular, $400 \mathrm{mg} / \mathrm{kg}$ EAP exhibited favorable inhibitory activities on decreases in gastrocnemius muscle thickness, which were comparable with the effects of oxymetholone $(50 \mathrm{mg} / \mathrm{kg})$. Data are presented as the mean \pm standard deviation of 8 mice. Oxymetholone was orally administered at $50 \mathrm{mg} / \mathrm{kg}$, dissolved in deionized distilled water. ${ }^{a} \mathrm{P}<0.01$ compared with the intact control group, as determined by LSD test. ${ }^{\mathrm{b}} \mathrm{P}<0.01$ compared with the DEXA control group, as determined by LSD test. DEXA, dexamethasone; EAP, extracellular polysaccharides purified from Aureobasidium pullulans SM-2001; LSD, least-significant difference.

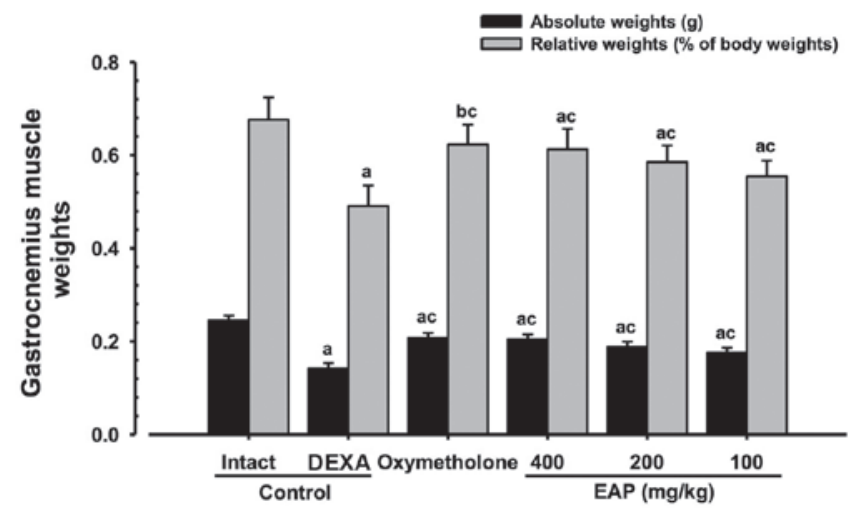

Figure 5. Alterations in gastrocnemius muscle weight in mice with DEXA-induced muscle atrophy. Significant decreases in absolute wet-weights and relative weights of gastrocnemius muscle mass were revealed in the DEXA control mice compared with in the intact vehicle control mice. However, significant increases in gastrocnemius muscle mass weights were observed in oxymetholone- and EAP-treated mice compared with in the DEXA control group. EAP (400, 200 and $100 \mathrm{mg} / \mathrm{kg}$ ) exhibited dose-dependent inhibitory effects on DEXA-induced decreases in gastrocnemius muscle weights; in particular, $400 \mathrm{mg} / \mathrm{kg}$ EAP exhibited favorable inhibitory activities on decreases in gastrocnemius muscle weights, which were comparable with the effects of oxymetholone $(50 \mathrm{mg} / \mathrm{kg})$. Data are presented as the mean \pm standard deviation of 8 mice. Oxymetholone was orally administered at $50 \mathrm{mg} / \mathrm{kg}$, dissolved in deionized distilled water. ${ }^{\mathrm{a}} \mathrm{P}<0.01$ and ${ }^{\mathrm{b}} \mathrm{P}<0.05$ compared with the intact control group, as determined by LSD test. ${ }^{\mathrm{c}} \mathrm{P}<0.01$ compared with the DEXA control group, as determined by LSD test. DEXA, dexamethasone; EAP, extracellular polysaccharides purified from Aureobasidium pullulans SM-2001; LSD, least-significant difference.

Effects on gastrocnemius muscle thickness after muscle exposure. Significant decreases $(\mathrm{P}<0.01)$ in gastrocnemius muscle thickness following muscle exposure were observed in the

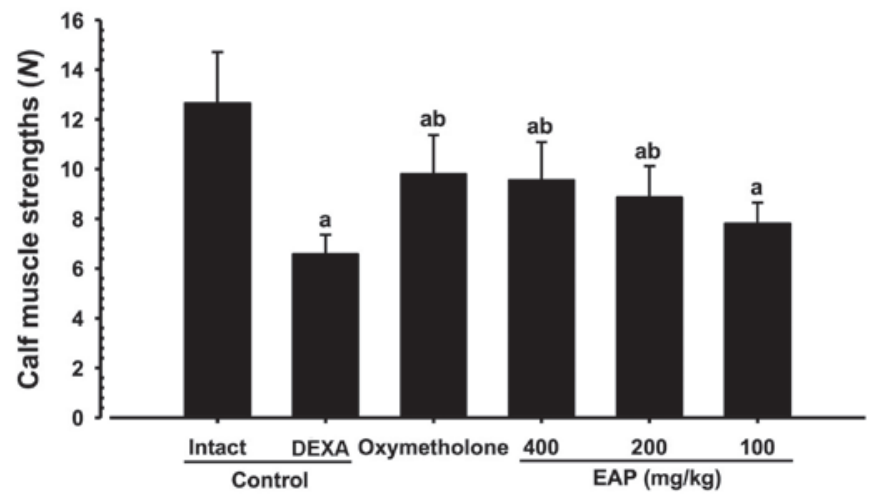

Figure 6. Alterations in calf muscle strength in mice with DEXA-induced muscle atrophy. Significant decreases in the tensile strength of calf muscles were revealed in the DEXA control mice compared with in the intact vehicle control mice. However, significant increases in calf muscle strength were observed in the $50 \mathrm{mg} / \mathrm{kg}$ oxymetholone-treated and 400 and $200 \mathrm{mg} / \mathrm{kg}$ EAP-treated mice compared with in the DEXA control group. In addition, $100 \mathrm{mg} / \mathrm{kg}$ EAP-treated mice exhibited non-significant increases in calf muscle strength compared with in the DEXA control mice. EAP (400, 200 and $100 \mathrm{mg} / \mathrm{kg}$ ) exhibited clear dose-dependent inhibitory effects on DEXA-induced decreases in calf muscle strength; in particular, $400 \mathrm{mg} / \mathrm{kg}$ EAP exhibited favorable inhibitory activities on decreases in calf muscle strength, which were comparable with the effects of oxymetholone $(50 \mathrm{mg} / \mathrm{kg})$. Data are presented as the mean \pm standard deviation of 8 mice. Oxymetholone was orally administered at $50 \mathrm{mg} / \mathrm{kg}$, dissolved in deionized distilled water. ${ }^{\text {ap }}<0.01$ compared with the intact control group, as determined by LSD test. ${ }^{b} \mathrm{P}<0.01$ compared with the DEXA control group, as determined by LSD test. DEXA, dexamethasone; EAP, extracellular polysaccharides purified from Aureobasidium pullulans SM-2001; LSD, least-significant difference.

DEXA control mice compared with in the intact vehicle control mice. However, significant increases $(\mathrm{P}<0.01)$ in gastrocnemius muscle thickness were detected in the mice treated with oxymetholone and all three doses of EAP compared with in the DEXA control group. EAP $(100,200$ and $400 \mathrm{mg} / \mathrm{kg})$ exhibited dose-dependent inhibitory effects on DEXA-induced decreases in gastrocnemius muscle thickness. In particular, $400 \mathrm{mg} / \mathrm{kg}$ EAP exhibited favorable inhibitory activities on gastrocnemius muscle thickness, which were comparable with the effects of $50 \mathrm{mg} / \mathrm{kg}$ oxymetholone (Figs. 3 and 4 ).

Effects on gastrocnemius muscle mass. Significant decreases $(\mathrm{P}<0.01)$ in relative weights and absolute wet weights of gastrocnemius muscle mass were demonstrated in the DEXA control mice compared with in the intact vehicle control mice. However, significant increases $(\mathrm{P}<0.01)$ in gastrocnemius muscle weights were observed in the oxymetholone-treated and 100, 200 and $400 \mathrm{mg} / \mathrm{kg}$ EAP-treated mice compared with in the DEXA control group. EAP doses (100, 200, and $400 \mathrm{mg} / \mathrm{kg}$ ) exhibited dose-dependent inhibitory effects on the DEXA-induced decreases in gastrocnemius muscle weights; in particular, $400 \mathrm{mg} / \mathrm{kg}$ EAP exhibited favorable inhibitory activities on gastrocnemius muscle weight, which were comparable with the effects of $50 \mathrm{mg} / \mathrm{kg}$ oxymetholone (Fig. 5).

Effects on calf muscle strength. Significant decreases $(\mathrm{P}<0.01)$ in the tensile strength of calf muscles were demonstrated in the DEXA control mice compared with in the intact vehicle control mice. However, significant increases $(\mathrm{P}<0.01)$ in calf muscle strength were observed in oxymetholone-treated and 200 and $400 \mathrm{mg} / \mathrm{kg}$ EAP-treated 
Table V. Alterations in the serum biochemistry of mice with DEXA-induced muscle atrophy.

\begin{tabular}{|c|c|c|c|}
\hline \multirow[b]{2}{*}{ Group } & \multicolumn{3}{|c|}{ Serum levels (units) } \\
\hline & Creatine (mg/dl) & Creatine kinase (IU/l) & LDH (IU/l) \\
\hline \multicolumn{4}{|l|}{ Controls } \\
\hline Intact & $0.33 \pm 0.06$ & $83.63 \pm 19.40$ & $647.25 \pm 131.86$ \\
\hline DEXA & $0.85 \pm 0.11^{\mathrm{a}}$ & $274.13 \pm 51.85^{\mathrm{b}}$ & $163.25 \pm 47.63^{\mathrm{a}}$ \\
\hline \multicolumn{4}{|l|}{ Reference } \\
\hline Oxymetholone & $0.45 \pm 0.05^{\mathrm{c}, \mathrm{d}}$ & $146.50 \pm 18.15^{\mathrm{b}, \mathrm{e}}$ & $304.13 \pm 71.06^{\mathrm{a}, \mathrm{d}}$ \\
\hline \multicolumn{4}{|l|}{ EAP-treated } \\
\hline $400 \mathrm{mg} / \mathrm{kg}$ & $0.49 \pm 0.09^{\mathrm{a}, \mathrm{d}}$ & $152.88 \pm 14.26^{\mathrm{b}, \mathrm{e}}$ & $294.00 \pm 42.81^{\mathrm{a}, \mathrm{d}}$ \\
\hline $200 \mathrm{mg} / \mathrm{kg}$ & $0.57 \pm 0.10^{\mathrm{a}, \mathrm{d}}$ & $176.63 \pm 15.40^{\mathrm{b}, \mathrm{e}}$ & $264.25 \pm 53.73^{\mathrm{a}, \mathrm{d}}$ \\
\hline $100 \mathrm{mg} / \mathrm{kg}$ & $0.66 \pm 0.13^{\mathrm{a}, \mathrm{d}}$ & $210.75 \pm 29.35^{\mathrm{b}, \mathrm{f}}$ & $242.50 \pm 29.24^{\mathrm{a}, \mathrm{g}}$ \\
\hline
\end{tabular}

Table VI. Alterations in the gastrocnemius muscle antioxidant defense system in mice with DEXA-induced muscle atrophy.

\begin{tabular}{|c|c|c|c|c|c|}
\hline \multirow[b]{2}{*}{ Group } & \multicolumn{5}{|c|}{ Activity levels (units) } \\
\hline & $\begin{array}{l}\text { Malondialdehyde } \\
\text { (nM/mg protein) }\end{array}$ & $\begin{array}{c}\text { Reactive oxygen species } \\
\text { (RFU/ } \mu \text { g protein) }\end{array}$ & $\begin{array}{c}\text { Glutathione } \\
\text { (nM/mg protein) }\end{array}$ & $\begin{array}{l}\text { Superoxide dismutase } \\
\text { (nM/min/mg protein) }\end{array}$ & $\begin{array}{c}\text { Catalase } \\
(\mathrm{U} / \mathrm{mg} \text { protein })\end{array}$ \\
\hline \multicolumn{6}{|l|}{ Controls } \\
\hline Intact & $1.84 \pm 0.76$ & $22.12 \pm 10.46$ & $0.64 \pm 0.15$ & $34.14 \pm 10.58$ & $7.08 \pm 2.11$ \\
\hline DEXA & $8.32 \pm 1.11^{\mathrm{a}}$ & $67.40 \pm 12.82^{\mathrm{a}}$ & $0.16 \pm 0.07^{\mathrm{a}}$ & $11.19 \pm 1.97^{\mathrm{b}}$ & $1.84 \pm 0.24^{\mathrm{b}}$ \\
\hline \multicolumn{6}{|l|}{ Reference } \\
\hline Oxymetholone & $4.44 \pm 1.05^{\mathrm{a}, \mathrm{c}}$ & $31.92 \pm 11.89^{c}$ & $0.37 \pm 0.09^{\mathrm{a}, \mathrm{c}}$ & $21.51 \pm 4.42^{\mathrm{b}, \mathrm{d}}$ & $3.64 \pm 0.70^{\mathrm{b}, \mathrm{d}}$ \\
\hline \multicolumn{6}{|l|}{ EAP-treated } \\
\hline $400 \mathrm{mg} / \mathrm{kg}$ & $4.48 \pm 1.20^{\mathrm{a}, \mathrm{c}}$ & $31.89 \pm 10.67^{c}$ & $0.38 \pm 0.10^{\mathrm{a}, \mathrm{c}}$ & $20.81 \pm 4.57^{\mathrm{b}, \mathrm{d}}$ & $3.56 \pm 0.83^{\mathrm{b}, \mathrm{d}}$ \\
\hline $200 \mathrm{mg} / \mathrm{kg}$ & $5.81 \pm 0.90^{\mathrm{a}, \mathrm{c}}$ & $37.31 \pm 10.21^{\mathrm{c}, \mathrm{e}}$ & $0.34 \pm 0.12^{\mathrm{a}, \mathrm{c}}$ & $18.94 \pm 4.46^{\mathrm{b}, \mathrm{d}}$ & $3.12 \pm 0.49^{\mathrm{b}, \mathrm{d}}$ \\
\hline $100 \mathrm{mg} / \mathrm{kg}$ & $6.42 \pm 0.76^{\mathrm{a}, \mathrm{c}}$ & $45.19 \pm 12.22^{\mathrm{a}, \mathrm{c}}$ & $0.29 \pm 0.08^{\mathrm{a}, \mathrm{f}}$ & $17.52 \pm 2.30^{\mathrm{b}, \mathrm{d}}$ & $2.70 \pm 0.52^{\mathrm{b}, \mathrm{d}}$ \\
\hline
\end{tabular}

Data are presented as the mean \pm standard deviation of 8 mice. Oxymetholone was orally administered at $50 \mathrm{mg} / \mathrm{kg}$, dissolved in distilled water. ${ }^{\mathrm{a}} \mathrm{P}<0.01$ compared with the intact control group, as determined by LSD test. ${ }^{\mathrm{b}} \mathrm{P}<0.01$ compared with the intact control group, as determined by MW test. ${ }^{c} \mathrm{P}<0.01$ compared with the DEXA control group, as determined by LSD test. ${ }^{\mathrm{d}} \mathrm{P}<0.01$ compared with the DEXA control group, as determined by MW test. ${ }^{e} \mathrm{P}<0.05$ compared with the intact control group, as determined by LSD test. ${ }^{\mathrm{f}} \mathrm{P}<0.05$ compared with the DEXA control group, as determined by LSD test. DEXA, dexamethasone; EAP, extracellular polysaccharides purified from Aureobasidium pullulans SM-2001; LSD, least-significant difference; MW, Mann Whitney U.

mice compared with in the DEXA control group. In addition, $100 \mathrm{mg} / \mathrm{kg}$ EAP-treated mice exhibited non-significant increases in calf muscle strength compared with in the DEXA control mice. EAP (100, 200 and $400 \mathrm{mg} / \mathrm{kg})$ exhibited dose-dependent inhibitory effects on DEXA-induced decreases in calf muscle strength; in particular, $400 \mathrm{mg} / \mathrm{kg}$ EAP exhibited favorable inhibitory activities on decreases in calf muscle strength, which were comparable with the effects of $50 \mathrm{mg} / \mathrm{kg}$ oxymetholone (Fig. 6).
Effects on serum biochemistry. Significant increases $(\mathrm{P}<0.01)$ in serum $\mathrm{CK}$ and creatine levels, and decreases in serum LDH levels, were demonstrated in the DEXA control mice compared with in the intact vehicle control mice. However, significant decreases $(\mathrm{P}<0.05)$ in serum $\mathrm{CK}$ and creatine levels were observed in oxymetholone- and EAP-treated mice compared with in the DEXA control group, alongside significant increases $(\mathrm{P}<0.05)$ in serum LDH levels. EAP (100, 200, and $400 \mathrm{mg} / \mathrm{kg}$ ) exhibited dose-dependent inhibitory effects on DEXA-induced increases 
Table VII. Alterations in gastrocnemius muscle mRNA expression in mice with DEXA-induced muscle atrophy.

\begin{tabular}{|c|c|c|c|c|c|c|}
\hline \multirow[b]{3}{*}{ Target } & \multicolumn{6}{|c|}{ Groups } \\
\hline & \multicolumn{2}{|c|}{ Controls } & \multirow{2}{*}{$\frac{\text { Reference }}{\text { Oxymetholone }}$} & \multicolumn{3}{|c|}{ EAP-treated mice $(\mathrm{mg} / \mathrm{kg})$} \\
\hline & Intact & DEXA & & 400 & 200 & 100 \\
\hline Atrogin-1 & $0.99 \pm 0.07$ & $4.90 \pm 0.67^{\mathrm{a}}$ & $2.20 \pm 0.44^{\mathrm{a}, \mathrm{b}}$ & $2.29 \pm 0.44^{\mathrm{a}, \mathrm{b}}$ & $3.24 \pm 0.66^{\mathrm{a}, \mathrm{b}}$ & $3.81 \pm 0.51^{\mathrm{a}, \mathrm{b}}$ \\
\hline MuRF 1 & $1.08 \pm 0.22$ & $6.15 \pm 0.97^{\mathrm{c}}$ & $2.96 \pm 0.54^{\mathrm{c}, \mathrm{d}}$ & $3.05 \pm 0.61^{\mathrm{c}, \mathrm{d}}$ & $3.54 \pm 0.83^{\mathrm{c}, \mathrm{d}}$ & $4.03 \pm 0.58^{\mathrm{c}, \mathrm{d}}$ \\
\hline PI3K p85a & $1.03 \pm 0.13$ & $0.62 \pm 0.09^{\mathrm{a}}$ & $1.13 \pm 0.39^{b}$ & $1.11 \pm 0.33^{\mathrm{b}}$ & $0.92 \pm 0.06^{\mathrm{b}, \mathrm{e}}$ & $0.84 \pm 0.13^{\mathrm{b}, \mathrm{e}}$ \\
\hline Akt1 & $1.01 \pm 0.06$ & $0.52 \pm 0.07^{\mathrm{c}}$ & $0.85 \pm 0.10^{\mathrm{c}, \mathrm{d}}$ & $0.85 \pm 0.09^{\mathrm{c}, \mathrm{d}}$ & $0.78 \pm 0.12^{\mathrm{c}, \mathrm{d}}$ & $0.70 \pm 0.10^{\mathrm{c}, \mathrm{d}}$ \\
\hline A1R & $1.03 \pm 0.14$ & $0.49 \pm 0.12^{\mathrm{c}}$ & $0.86 \pm 0.06^{\mathrm{c}, \mathrm{d}}$ & $0.86 \pm 0.11^{\mathrm{c}, \mathrm{d}}$ & $0.72 \pm 0.08^{\mathrm{c}, \mathrm{d}}$ & $0.67 \pm 0.12^{\mathrm{c}, \mathrm{d}}$ \\
\hline TRPV4 & $1.09 \pm 0.10$ & $0.35 \pm 0.08^{c}$ & $0.65 \pm 0.10^{\mathrm{c}, \mathrm{d}}$ & $0.68 \pm 0.15^{\mathrm{c}, \mathrm{d}}$ & $0.61 \pm 0.11^{\mathrm{c}, \mathrm{d}}$ & $0.52 \pm 0.13^{\mathrm{c}, \mathrm{d}}$ \\
\hline Myostatin & $1.01 \pm 0.09$ & $6.88 \pm 0.89^{\mathrm{a}}$ & $3.16 \pm 0.73^{\mathrm{a}, \mathrm{b}}$ & $3.17 \pm 0.59^{\mathrm{a}, \mathrm{b}}$ & $3.95 \pm 0.73^{\mathrm{a}, \mathrm{b}}$ & $4.36 \pm 1.18^{\mathrm{a}, \mathrm{b}}$ \\
\hline SIRT1 & $1.01 \pm 0.18$ & $10.49 \pm 2.97^{\mathrm{a}}$ & $3.66 \pm 1.13^{\mathrm{a}, \mathrm{b}}$ & $3.49 \pm 1.00^{\mathrm{a}, \mathrm{b}}$ & $4.72 \pm 1.61^{\mathrm{a}, \mathrm{b}}$ & $5.28 \pm 1.15^{\mathrm{a}, \mathrm{b}}$ \\
\hline
\end{tabular}

Data are presented as the mean \pm standard deviation of 8 mice. Expression levels were normalized to 18S ribosomal RNA expression. Oxymetholone was orally administered at $50 \mathrm{mg} / \mathrm{kg}$ levels, dissolved in distilled water. ${ }^{\mathrm{P}}<0.01$ compared with the intact control group, as determined by MW test. ${ }^{\mathrm{b}} \mathrm{P}<0.01$ compared with the DEXA control group, as determined by MW test. ${ }^{\mathrm{C}} \mathrm{P}<0.01$ compared with the intact control group, as determined by LSD test. ${ }^{\mathrm{d}} \mathrm{P}<0.01$ compared with the DEXA control group, as determined by LSD test. ${ }^{\mathrm{e}} \mathrm{P}<0.05$ compared with the intact control group, as determined by MW test. A1R, adenosine A1 receptor; Akt1, AKT serine/threonine kinase 1; DEXA, dexamethasone; EAP, extracellular polysaccharides purified from Aureobasidium pullulans SM-2001; LSD, least-significant difference; MuRF1, muscle RING-finger protein-1; MW, Mann Whitney U; PI3K, phosphatidylinositol 3-kinase; SIRT1, sirtuin 1; TRPV4, transient receptor potential cation cannel subfamily $\mathrm{V}$ member 4.

in serum CK and creatine levels, and decreases in serum LDH levels. In particular, $400 \mathrm{mg} / \mathrm{kg}$ EAP exhibited favorable inhibitory activities on serum CK and creatine level elevations, and decreases in serum LDH levels, which were comparable with the effects of $50 \mathrm{mg} / \mathrm{kg}$ oxymetholone (Table V).

Effects on gastrocnemius muscle antioxidant defense systems Alterations in muscle MDA levels. Significant increases $(\mathrm{P}<0.01)$ in MDA levels were observed in the DEXA control group compared with in the intact control group. However, the elevations in MDA levels were significantly $(\mathrm{P}<0.01)$ and dose-dependently decreased following treatment with EAP. Gastrocnemius muscle lipid peroxidation in oxymetholone-treated mice was also significantly decreased $(\mathrm{P}<0.01)$ compared with in the control mice. In particular, $400 \mathrm{mg} / \mathrm{kg}$ EAP exhibited favorable inhibitory activities on DEXA-induced increases in muscle lipid peroxidation, which were comparable with the effects of $50 \mathrm{mg} / \mathrm{kg}$ oxymetholone (Table VI).

Alterations in muscle ROS content. Significant increases $(\mathrm{P}<0.01)$ in muscle ROS content were observed in the DEXA control group compared with in the intact control group. However, elevated ROS levels were significantly and dose-dependently decreased $(\mathrm{P}<0.01)$ following treatment with EAP. In addition, gastrocnemius muscle ROS levels were significantly $(\mathrm{P}<0.01)$ inhibited in $50 \mathrm{mg} / \mathrm{kg}$ oxymetholone-treated mice compared with in the DEXA control mice. In particular, $400 \mathrm{mg} / \mathrm{kg}$ EAP exhibited favorable inhibitory activities on DEXA-induced muscle ROS elevations, which were comparable with the effects of oxymetholone (Table VI).

Alterations in muscle GSH content. Significant decreases $(\mathrm{P}<0.01)$ in the levels of the endogenous antioxidant, GSH, were detected in the DEXA control group compared with in the intact control group. However, these decreases in muscle GSH were significantly $(\mathrm{P}<0.05)$ inhibited following 24 days of oral treatment with oxymetholone, and 100, 200 and $400 \mathrm{mg} / \mathrm{kg}$ EAP. EAP increased gastrocnemius muscle GSH content in a dose-dependent manner compared with in the DEXA control mice. In particular, $400 \mathrm{mg} / \mathrm{kg}$ EAP exhibited favorable inhibitory activities on DEXA-induced decreases in muscle GSH content, which were comparable with the effects of oxymetholone (Table VI).

Alterations in muscle SOD activity. Significant decreases $(\mathrm{P}<0.01)$ in the activity levels of the endogenous antioxidant enzyme, SOD, were detected in the DEXA control group compared with in the intact control group. However, significant increases $(\mathrm{P}<0.01)$ in SOD activity were observed in oxymetholone-treated, and 100, 200 and $400 \mathrm{mg} / \mathrm{kg}$ EAP-treated mice compared with in the DEXA control mice. EAP exerted dose-dependent increases on SOD activity in gastrocnemius muscles compared with in the DEXA control mice. In particular, $400 \mathrm{mg} / \mathrm{kg}$ EAP exhibited favorable inhibitory activities on DEXA-induced decreases in SOD activity levels, which were comparable with the effects of $50 \mathrm{mg} / \mathrm{kg}$ oxymetholone (Table VI).

Alterations in muscle CAT activity. Significant decreases $(\mathrm{P}<0.01)$ in the activity levels of the endogenous antioxidant enzyme, CAT, were detected in the DEXA control group compared with in the intact control group. However, these decreases in muscle CAT activity were significantly and dose-dependently inhibited $(\mathrm{P}<0.01)$ following 24 days of oral treatment with EAP. Gastrocnemius muscle CAT activity levels in $50 \mathrm{mg} / \mathrm{kg}$ oxymetholone-treated mice were also significantly increased $(\mathrm{P}<0.01)$ compared with in the DEXA control mice. In particular, $400 \mathrm{mg} / \mathrm{kg}$ EAP exhibited favorable inhibitory activities on DEXA-induced decreases in 

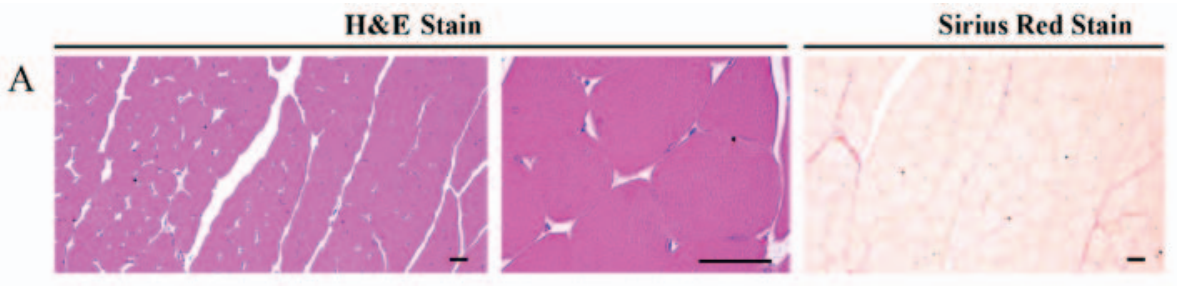

B
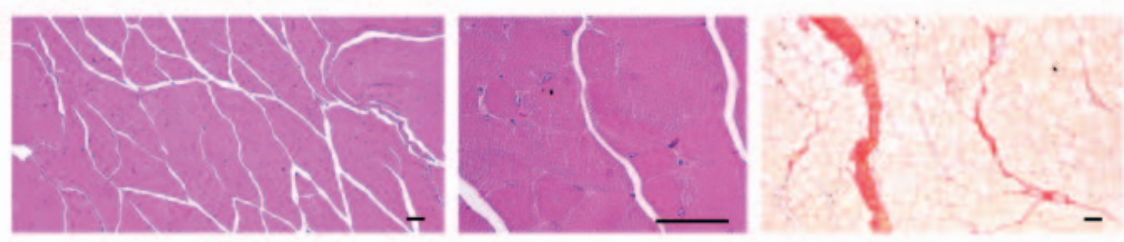

$\mathrm{C}$
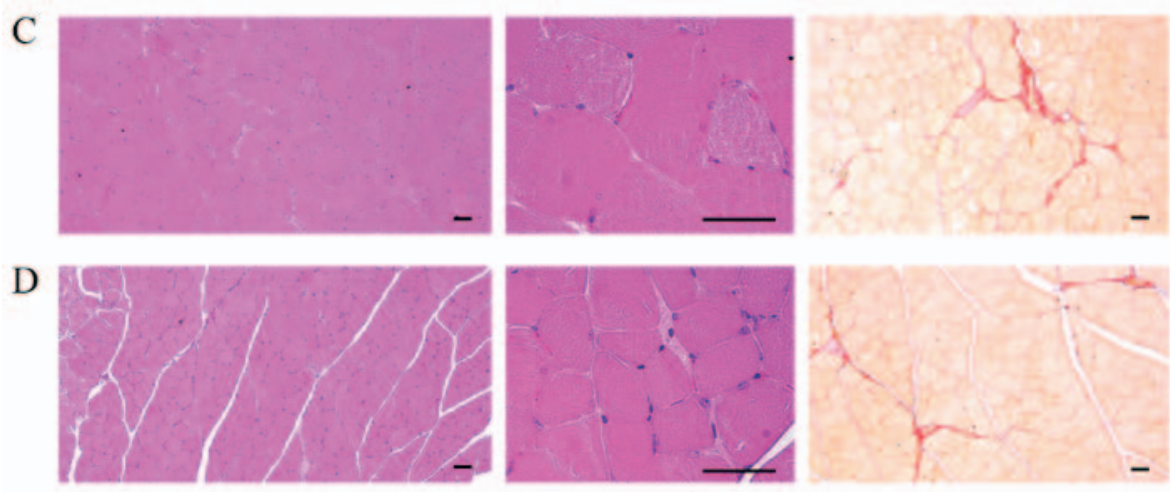

$\mathrm{E}$
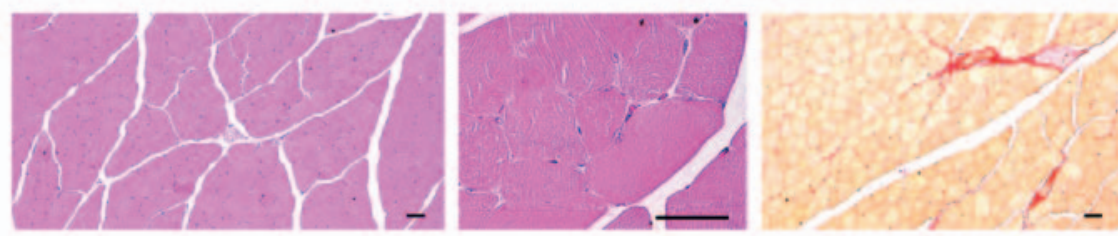

F
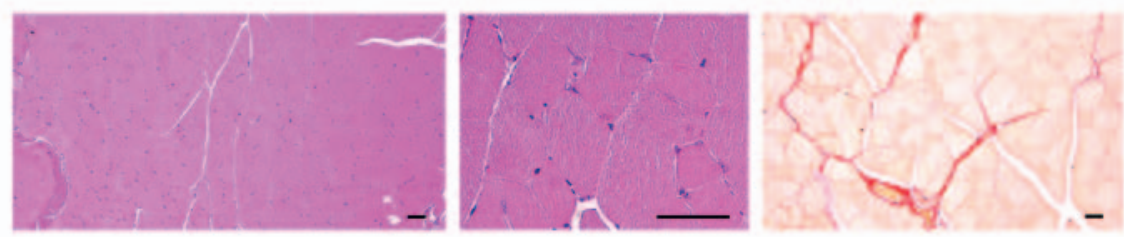

Figure 7. Representative gastrocnemius muscle histology. Marked catabolic muscular atrophy-associated alterations, including microvacuolation, reduced muscle fibers and focal fibrosis in muscle bundles were induced by treatment with DEXA; accordingly, significant decreases in mean muscle fiber diameters and increases in collagen fiber-occupied region percentages in muscle bundles were detected in the DEXA control mice compared with in the intact control mice. However, these DEXA treatment-associated catabolic atrophic alterations to gastrocnemius muscles were significantly and dose-dependently decreased following treatment with EAP. In addition, the muscular atrophic alterations were significantly reduced in $50 \mathrm{mg} / \mathrm{kg}$ oxymetholone-treated mice compared with in the DEXA control mice. In particular, $400 \mathrm{mg} / \mathrm{kg}$ EAP exhibited favorable inhibitory activities on DEXA-induced decreases in mean muscle fiber diameter and increases in collagen fiber-occupied region percentages in muscle bundles, which were comparable with the effects of oxymetholone $(50 \mathrm{mg} / \mathrm{kg})$. (A) Deionized distilled water-administered and saline-treated mice (intact vehicle control group). (B) Deionized distilled water-administered and DEXA-treated control mice (DEXA control group). (C) Oxymetholone $(50 \mathrm{mg} / \mathrm{kg}$ )-administered and DEXA-treated reference mice (oxymetholone group). (D) EAP (400 mg/kg)-administered and DEXA-treated experimental mice (EAP400 group). (E) EAP (200 mg/kg)-administered and DEXA-treated experimental mice (EAP200 group). (F) EAP (100 mg/kg)-administered and DEXA-treated experimental mice (EAP100 group). Scale bars=40 $\mu \mathrm{m}$. DEXA, dexamethasone; EAP, extracellular polysaccharides purified from Aureobasidium pullulans SM-2001.

muscle CAT activity levels, which were comparable with the effects of $50 \mathrm{mg} / \mathrm{kg}$ oxymetholone (Table VI).

Effects on gastrocnemius muscle mRNA expression. Significant alterations $(\mathrm{P}<0.01)$ in the mRNA expression levels of atrogin-1, MuRF1, PI3K, Akt1, A1R, TRPV4, myostatin and SIRT1 were detected in the gastrocnemius muscles of the DEXA control group compared with in the intact control group. However, these alterations in muscle atrogin-1, MuRF1, PI3K, Akt1, A1R, TRPV4, myostatin and SIRT1 expression were significantly reversed $(\mathrm{P}<0.05)$, in a dose-dependent manner, by treatment with EAP. In addition, the mRNA expression levels of atrogin-1, MuRF1, PI3K, Akt1, A1R, TRPV4, myostatin and SIRT1 in gastrocnemius muscle tissues, were significantly reversed in $50 \mathrm{mg} / \mathrm{kg}$ oxymetholone-treated mice $(\mathrm{P}<0.01)$ compared with in the DEXA control mice. In particular, $400 \mathrm{mg} / \mathrm{kg}$ EAP exhibited favorable activities on DEXA-induced alterations in muscle atrogin-1, MuRF1, PI3K, Akt1, A1R, TRPV4, myostatin and SIRT1 mRNA expression, which were comparable with the effects of $50 \mathrm{mg} / \mathrm{kg}$ oxymetholone (Table VII). 
Table VIII. Alterations in gastrocnemius muscle histomorphometry in mice with DEXA-induced muscle atrophy.

\begin{tabular}{|c|c|c|c|c|c|c|}
\hline \multirow[b]{3}{*}{ Variable } & \multicolumn{6}{|c|}{ Groups } \\
\hline & \multicolumn{2}{|c|}{ Controls } & \multirow{2}{*}{$\frac{\text { Reference }}{\text { Oxymetholone }}$} & \multicolumn{3}{|c|}{ EAP-treated mice $(\mathrm{mg} / \mathrm{kg})$} \\
\hline & Intact & DEXA & & 400 & 200 & 100 \\
\hline \multicolumn{7}{|c|}{ General histomorphometry } \\
\hline Fiber diameter $(\mu \mathrm{m})$ & $51.36 \pm 10.37$ & $23.35 \pm 5.26^{\mathrm{a}}$ & $38.03 \pm 6.72^{\mathrm{a}, \mathrm{b}}$ & $37.39 \pm 7.30^{\mathrm{a}, \mathrm{b}}$ & $34.77 \pm 6.65^{a, b}$ & $31.87 \pm 4.30^{\mathrm{a}, \mathrm{c}}$ \\
\hline Collagen $(\%)$ & $4.09 \pm 1.71$ & $31.96 \pm 4.71^{\mathrm{d}}$ & $16.72 \pm 3.30^{\mathrm{d}, e}$ & $15.93 \pm 4.62^{\mathrm{d}, \mathrm{e}}$ & $19.36 \pm 3.02^{\mathrm{d}, \mathrm{e}}$ & $23.57 \pm 5.64^{\mathrm{d}, \mathrm{f}}$ \\
\hline \multicolumn{7}{|c|}{ Immunohistomorphometry (fibers $/ \mathrm{mm}^{2}$ ) } \\
\hline Caspase-3 & $2.13 \pm 2.53$ & $41.13 \pm 10.45^{\mathrm{a}}$ & $20.88 \pm 5.03^{\mathrm{a}, \mathrm{b}}$ & $19.00 \pm 2.83^{\mathrm{a}, \mathrm{b}}$ & $23.63 \pm 5.26^{\mathrm{a}, \mathrm{b}}$ & $28.00 \pm 6.55^{\mathrm{a}, \mathrm{b}}$ \\
\hline PARP & $4.88 \pm 2.59$ & $75.00 \pm 12.94^{\mathrm{a}}$ & $32.13 \pm 10.25^{\mathrm{a}, \mathrm{b}}$ & $31.25 \pm 10.94^{\mathrm{a}, \mathrm{b}}$ & $38.63 \pm 14.34^{\mathrm{a}, \mathrm{b}}$ & $48.50 \pm 12.04^{\mathrm{a}, \mathrm{b}}$ \\
\hline Nitrotyrosine & $5.63 \pm 2.67$ & $67.75 \pm 12.37^{\mathrm{a}}$ & $34.63 \pm 13.09^{\mathrm{a}, \mathrm{b}}$ & $31.38 \pm 14.51^{\mathrm{a}, \mathrm{b}}$ & $38.25 \pm 15.18^{\mathrm{a}, \mathrm{b}}$ & $46.00 \pm 13.31^{\mathrm{a}, \mathrm{b}}$ \\
\hline 4-HNE & $3.75 \pm 1.91$ & $75.38 \pm 11.67^{\mathrm{a}}$ & $42.25 \pm 10.50^{\mathrm{a}, \mathrm{b}}$ & $40.38 \pm 10.14^{\mathrm{a}, \mathrm{b}}$ & $45.75 \pm 10.98^{\mathrm{a}, \mathrm{b}}$ & $53.50 \pm 10.60^{\mathrm{a}, \mathrm{b}}$ \\
\hline iNOS & $7.63 \pm 2.77$ & $50.25 \pm 11.85^{\mathrm{d}}$ & $20.38 \pm 4.63^{\mathrm{d}, \mathrm{e}}$ & $16.25 \pm 3.54^{\mathrm{d}, \mathrm{e}}$ & $27.63 \pm 7.85^{\mathrm{d}, \mathrm{e}}$ & $32.75 \pm 8.76^{\mathrm{d}, \mathrm{e}}$ \\
\hline Myostatin & $1.13 \pm 0.83$ & $51.88 \pm 11.15^{\mathrm{d}}$ & $21.75 \pm 4.83^{\mathrm{d}, \mathrm{e}}$ & $20.38 \pm 5.40^{\mathrm{d}, \mathrm{e}}$ & $32.75 \pm 4.98^{\mathrm{d}, \mathrm{e}}$ & $36.38 \pm 7.63^{\mathrm{d}, \mathrm{e}}$ \\
\hline
\end{tabular}

Data are presented as the mean \pm standard deviation of 8 mice. Oxymetholone was orally administered at $50 \mathrm{mg} / \mathrm{kg}$, dissolved in distilled water. ${ }^{\mathrm{a}} \mathrm{P}<0.01$ compared with the intact control group, as determined by LSD test. ${ }^{\mathrm{b}} \mathrm{P}<0.01$ and ${ }^{\mathrm{c}} \mathrm{P}<0.05$ compared with the DEXA control group, as determined by LSD test. ${ }^{\mathrm{d}} \mathrm{P}<0.01$ compared with the intact control group, as determined by $\mathrm{MW}$ test. ${ }^{\mathrm{e}} \mathrm{P}<0.01$ and ${ }^{\mathrm{f}} \mathrm{P}<0.05$ compared with the DEXA control group, as determined by MW test. 4-HNE, 4-hydroxynonenal; DEXA, dexamethasone; EAP, extracellular polysaccharides purified from Aureobasidium pullulans SM-2001; LSD, least-significant difference; MW, Mann Whitney U; iNOS, inducible nitric oxide synthase; PARP, cleaved poly (ADP-ribose) polymerase.

Effects on gastrocnemius muscle histopathology. Marked alterations associated with catabolic muscle atrophy, including focal fibrosis in muscle bundles, microvacuolation and diminished muscle fibers, were induced by treatment with DEXA in the control mice. Accordingly, significant decreases $(\mathrm{P}<0.01)$ in mean muscle fiber diameters and increases in collagen fiber-occupied region percentages in muscle bundles were detected in the DEXA control mice compared with in the intact control mice. However, these DEXA treatment-associated catabolic alterations were significantly $(\mathrm{P}<0.05)$ and dose-dependently decreased following treatment with EAP. The muscle atrophy-associated alterations were also significantly inhibited $(\mathrm{P}<0.01)$ in $50 \mathrm{mg} / \mathrm{kg}$ oxymetholone-treated mice compared with in the DEXA control mice. In particular, $400 \mathrm{mg} / \mathrm{kg}$ EAP exhibited favorable inhibitory activities on DEXA-induced decreases in mean muscle fiber diameters and increases in collagen fiber-occupied regions in muscle bundles, which were comparable with the effects of oxymetholone (Table VIII and Fig. 7).

\section{Effects on gastrocnemius muscle immunohistochemistry}

Alterations in caspase-3-immunolabelled muscle fibers. Significant increases $(\mathrm{P}<0.01)$ in caspase-3 (apoptotic marker) immunoreactivity in gastrocnemius muscle bundles were observed in the DEXA control mice. EAP significantly and dose-dependently reduced $(\mathrm{P}<0.01)$ these DEXA-induced increases in caspase-3-immunoreactive muscle fibers. Oxymetholone also significantly decreased $(\mathrm{P}<0.01)$ the number of caspase-3-positive muscle fibers compared with in the DEXA control mice. In particular, $400 \mathrm{mg} / \mathrm{kg}$ EAP exhibited favorable inhibitory activities on DEXA-induced increases in caspase-3 immunoreactivity, which were comparable with the effects of $50 \mathrm{mg} / \mathrm{kg}$ oxymetholone (Table VIII and Fig. 8).
Alterations in PARP-immunolabelled muscle fibers. Significant increases $(\mathrm{P}<0.01)$ in PARP (apoptotic marker) immunoreactivity in gastrocnemius muscle bundles were observed in the DEXA control mice. EAP significantly and dose-dependently reduced $(\mathrm{P}<0.01)$ these DEXA-induced increases in PARP-immunoreactive muscle fibers. Oxymetholone also significantly decreased $(\mathrm{P}<0.01)$ the number of PARP-positive muscle fibers compared with in the DEXA control mice. In particular, $400 \mathrm{mg} / \mathrm{kg}$ EAP exhibited favorable inhibitory activities on DEXA-induced increases in PARP immunoreactivity, which were comparable with the effects of oxymetholone (Table VIII and Fig. 8).

Alterations in nitrotyrosine-immunolabelled muscle fibers. Significant increases $(\mathrm{P}<0.01)$ in nitrotyrosine (iNOS-associated oxidative stress marker) immunoreactivity in gastrocnemius muscle bundles were observed in the DEXA control mice. EAP significantly and dose-dependently reduced $(\mathrm{P}<0.01)$ these $\mathrm{DEXA}$-induced increases in the number of nitrotyrosine-immunoreactive muscle fibers. Oxymetholone also significantly decreased $(\mathrm{P}<0.01)$ the number of nitrotyrosine-positive muscle fibers compared with in the DEXA control mice. In particular, $400 \mathrm{mg} / \mathrm{kg}$ EAP exhibited favorable inhibitory activities on DEXA-induced increases in nitrotyrosine immunoreactivity, which were comparable with the effects of oxymetholone (Table VIII and Fig. 9).

Alterations in 4-HNE-immunolabelled muscle fibers. Significant increases $(\mathrm{P}<0.01)$ in 4 -HNE (lipid peroxidation marker) immunoreactivity in gastrocnemius muscle bundles were observed in the DEXA control mice. EAP significantly and dose-dependently reduced $(\mathrm{P}<0.01)$ these DEXA-induced increases in muscle 4-HNE-immunoreactive 


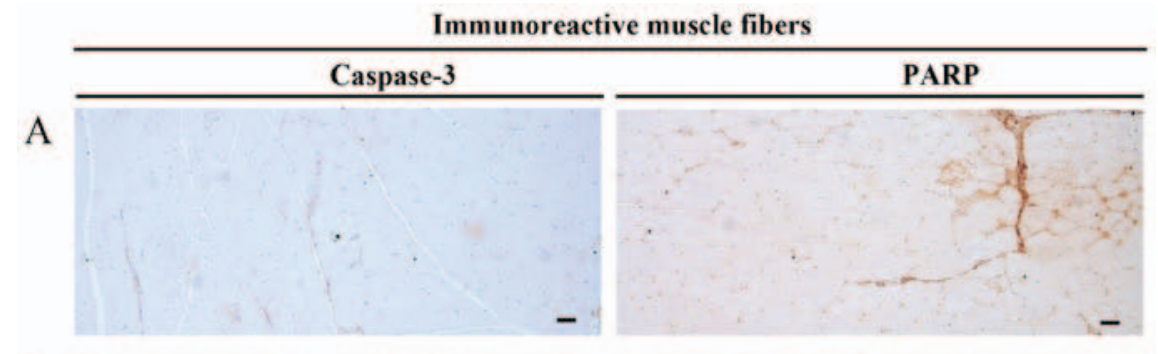

B

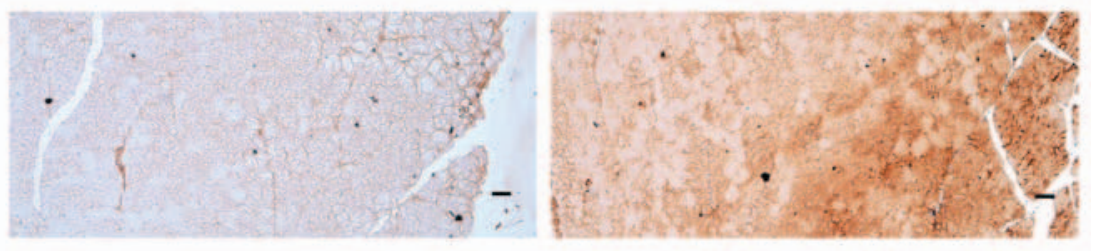

C

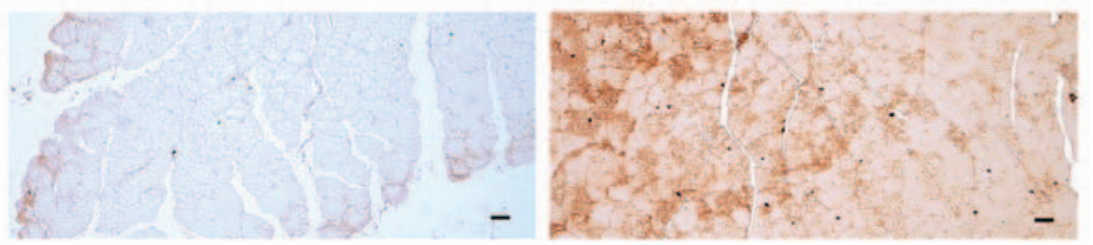

D
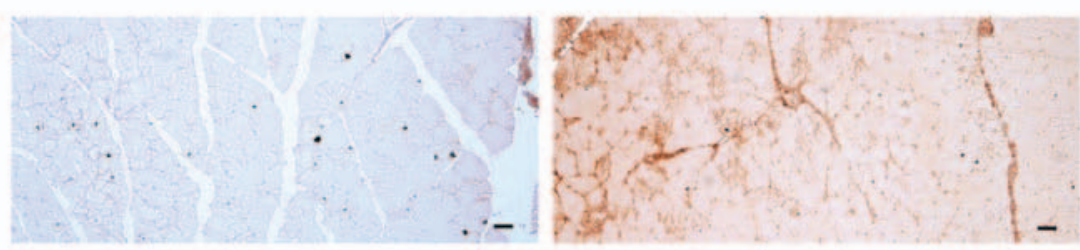

E
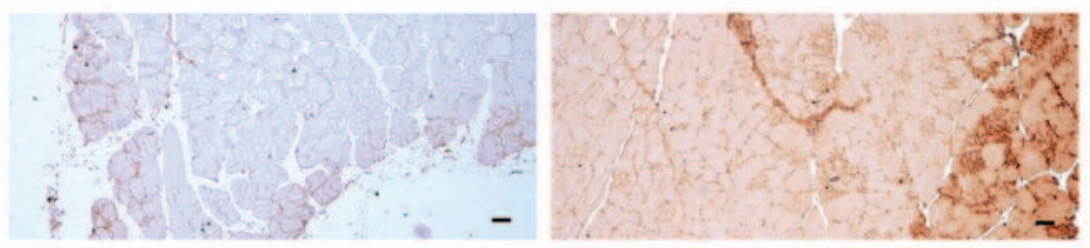

$\mathrm{F}$

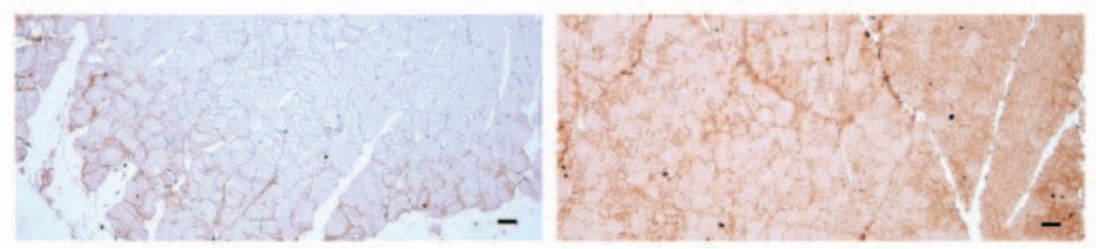

Figure 8. Representative gastrocnemius muscle caspase-3 and PARP immunoreactivity. Marked increases in the immunoreactivity of the apoptotic markers, caspase-3 and PARP, were detected in gastrocnemius muscle bundles from DEXA control mice. EAP dose-dependently and significantly reduced these DEXA-induced increases in muscular caspase-3- and PARP-immunoreactive muscle fibers. In addition, oxymetholone (50 mg/kg) significantly reduced the number of caspase-3- and PARP-positive muscle fibers compared with in the DEXA control mice. In particular, 400 mg/kg EAP exhibited favorable inhibitory activities on DEXA-induced increases in caspase-3-and PARP-immunoreactive fibers, which were comparable with the effects of oxymetholone $(50 \mathrm{mg} / \mathrm{kg})$. (A) Deionized distilled water-administered and saline-treated mice (intact vehicle control group). (B) Deionized distilled water-administered and DEXA-treated control mice (DEXA control group). (C) Oxymetholone $(50 \mathrm{mg} / \mathrm{kg}$ )-administered and DEXA-treated reference mice (oxymetholone group). (D) EAP (400 mg/kg)-administered and DEXA-treated experimental mice (EAP400 group). (E) EAP (200 mg/kg)-administered and DEXA-treated experimental mice (EAP200 group). (F) EAP (100 mg/kg)-administered and DEXA-treated experimental mice (EAP100 group). Scale bars=40 $\mu \mathrm{m}$. DEXA, dexamethasone; EAP, extracellular polysaccharides purified from Aureobasidium pullulans SM-2001; PARP, cleaved poly(ADP-ribose) polymerase.

fibers. Oxymetholone also significantly decreased $(\mathrm{P}<0.01)$ the number of 4-HNE-positive muscle fiber compared with in the DEXA control mice. In particular, $400 \mathrm{mg} / \mathrm{kg}$ EAP exhibited favorable inhibitory activities on DEXA-induced increases in 4-HNE-immunoreactive fibers, which were comparable with the effects of oxymetholone (Table VIII and Fig. 9).

Alterations in iNOS-immunolabelled muscle fibers. Significant increases $(\mathrm{P}<0.01)$ in iNOS (oxidative stress marker) immunoreactivity in gastrocnemius muscle bundles were observed in the DEXA control mice. EAP significantly and dose-dependently reduced $(\mathrm{P}<0.01)$ these DEXA-induced increases in muscle iNOS-immunoreactive fibers. Oxymetholone also significantly decreased $(\mathrm{P}<0.01)$ the number of iNOS-positive muscle fibers compared with in the DEXA control mice. In particular, $400 \mathrm{mg} / \mathrm{kg}$ EAP exhibited favorable inhibitory activities on DEXA-induced increases in iNOS-immunoreactive fibers, which were comparable with the effects of oxymetholone (Table VIII and Fig. 10). 


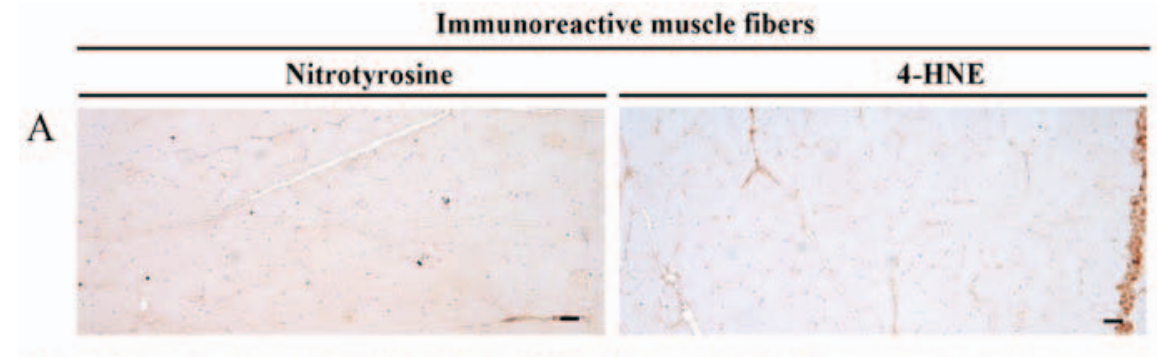

B
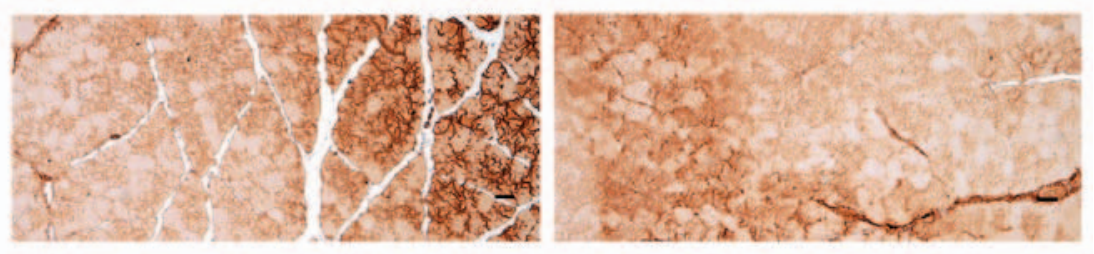

$\mathrm{C}$
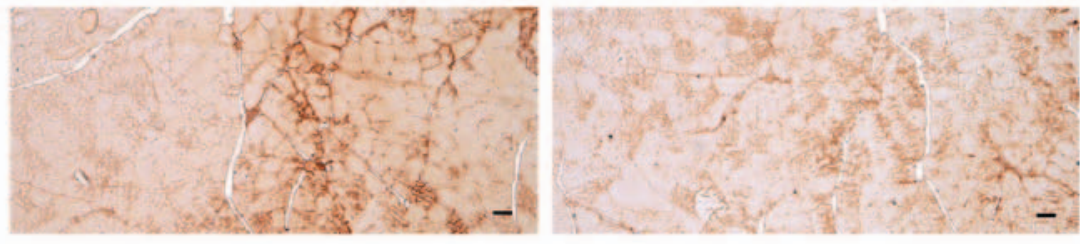

D
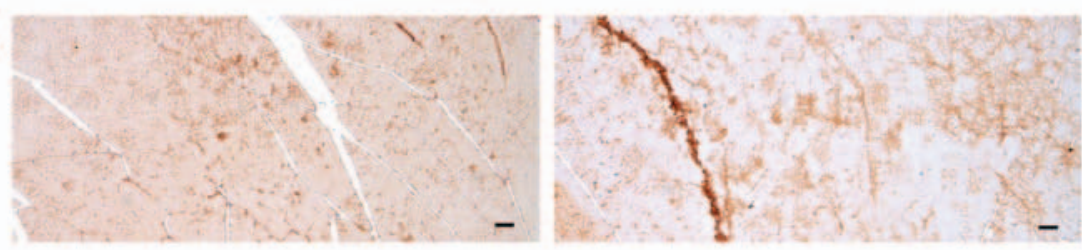

E
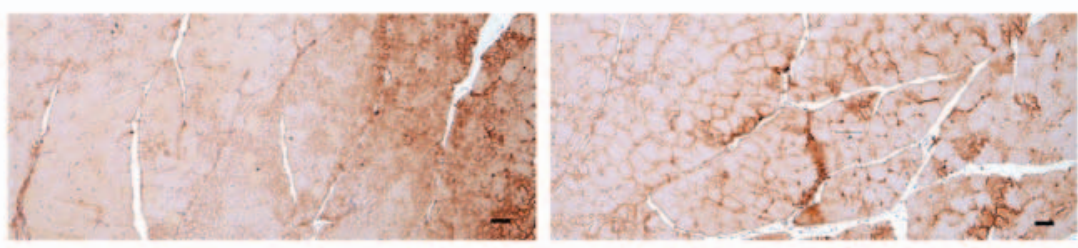

$\mathrm{F}$
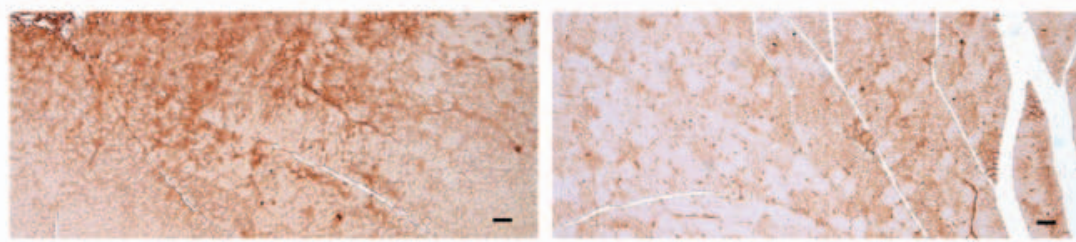

Figure 9. Representative gastrocnemius muscle nitrotyrosine and 4-HNE immunoreactivity. Marked increases in the immunoreactivity of the oxidative stress marker, nitrotyrosine, and the lipid peroxidation marker, 4-HNE, were detected in the gastrocnemius muscle bundles from DEXA control mice. However, EAP dose-dependently and significantly reduced these DEXA-induced increases in nitrotyrosine- and 4-HNE-immunoreactive fibers. In addition, oxymetholone $(50 \mathrm{mg} / \mathrm{kg})$ significantly reduced the number of nitrotyrosine- and 4-HNE-positive muscle fibers as compared with in the DEXA control mice. In particular, $400 \mathrm{mg} / \mathrm{kg}$ EAP exhibited favorable inhibitory activities on DEXA-induced increases in nitrotyrosine- and 4-HNE-immunoreactive fibers, which were comparable with the effects of oxymetholone (50 mg/kg). (A) Deionized distilled water-administered and saline-treated mice (intact vehicle control group). (B) Deionized distilled water-administered and DEXA-treated control mice (DEXA control group). (C) Oxymetholone (50 mg/kg)-administered and DEXA-treated reference mice (oxymetholone group). (D) EAP (400 mg/kg)-administered and DEXA-treated experimental mice (EAP400 group). (E) EAP (200 mg/kg)-administered and DEXA-treated experimental mice (EAP200 group). (F) EAP (100 mg/kg)-administered and DEXA-treated experimental mice (EAP100 group). Scale bars $=40 \mu \mathrm{m}$. 4-HNE, 4-hydroxynonenal; DEXA, dexamethasone; EAP, extracellular polysaccharides purified from Aureobasidium pullulans SM-2001.

Alterations in myostatin-immunolabelled muscle fibers. Significant increases $(\mathrm{P}<0.01)$ in myostatin immunoreactivity in gastrocnemius muscle bundles were observed in the DEXA control mice. EAP significantly and dose-dependently reduced $(\mathrm{P}<0.05)$ these DEXA-induced increases in myostatin-immunoreactive muscle fibers. Oxymetholone also significantly decreased $(\mathrm{P}<0.01)$ the number of myostatin-positive muscle fibers compared with in the DEXA control mice. In particular, $400 \mathrm{mg} / \mathrm{kg}$ EAP exhibited favorable inhibitory activities on
DEXA-induced increases in myostatin-immunoreactive fibers, which were comparable with the effects of oxymetholone (Table VIII and Fig. 10).

\section{Discussion}

Atrophy begins with a decrease in muscle tension, which is associated with reduced protein synthesis and increased protein degradation (68). Four types of proteolytic degradation 


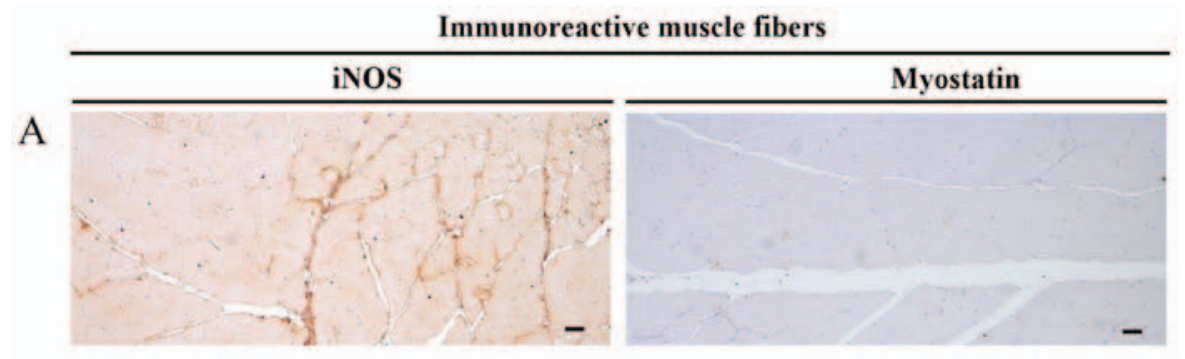

B
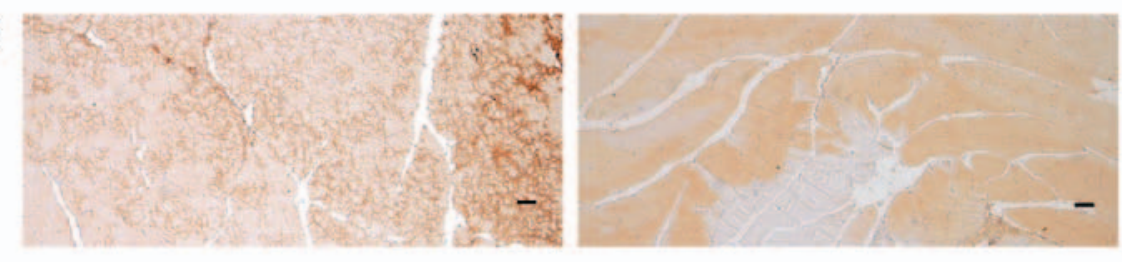

$\mathrm{C}$
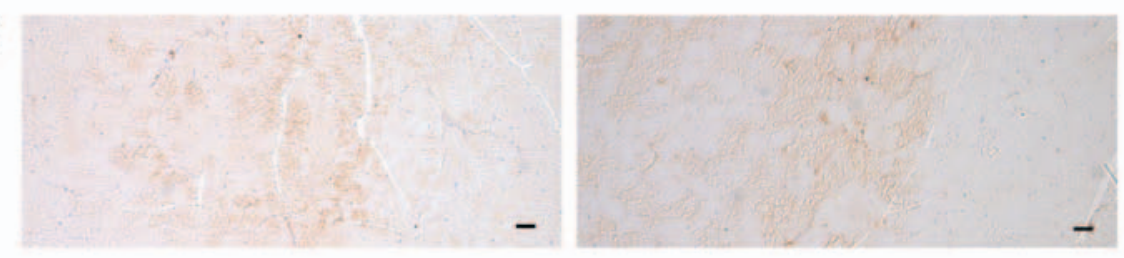

D
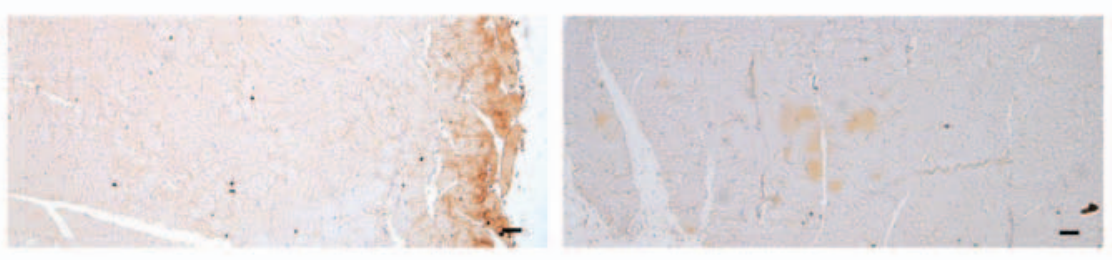

$\mathrm{E}$
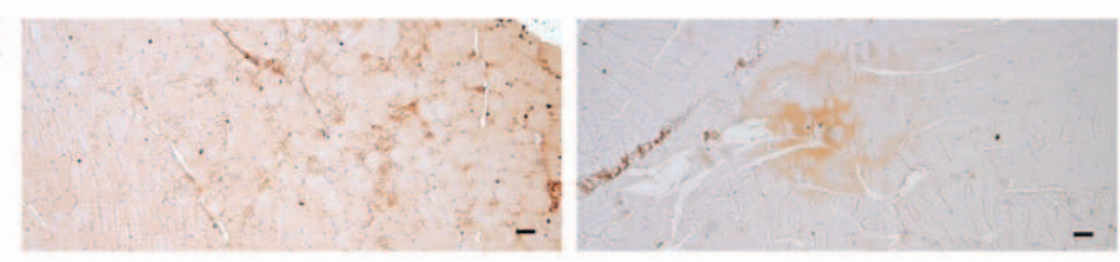

F
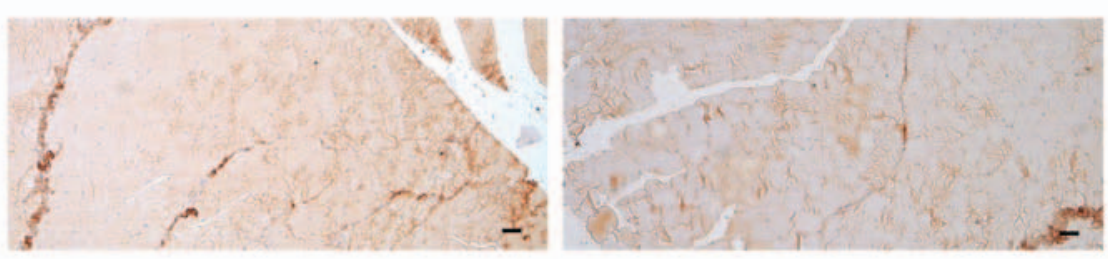

Figure 10. Representative gastrocnemius muscle iNOS and myostatin immunoreactivity. Marked increases in the immunoreactivity of the oxidative stress marker, iNOS, which is a strong negative regulator of muscle growth, and myostatin, were detected in the gastrocnemius muscle bundles from DEXA control mice. However, EAP significantly and dose-dependently reduced these DEXA-induced increases in iNOS- and myostatin-immunoreactive muscle fibers. In addition, oxymetholone $(50 \mathrm{mg} / \mathrm{kg}$ ) significantly decreased the number of iNOS- and myostatin-positive muscle fibers compared with in the DEXA control mice. In particular, $400 \mathrm{mg} / \mathrm{kg}$ EAP exhibited favorable inhibitory activities on DEXA-induced increases in iNOS- and myostatin-immunoreactive fibers, which were comparable with the effects of oxymetholone $(50 \mathrm{mg} / \mathrm{kg}$ ). (A) Deionized distilled water-administered and saline-treated mice (intact vehicle control group). (B) Deionized distilled water-administered and DEXA-treated control mice (DEXA control group). (C) Oxymetholone (50 mg/kg)-administered and DEXA-treated reference mice (oxymetholone group). (D) EAP $(400 \mathrm{mg} / \mathrm{kg}$ )-administered and DEXA-treated experimental mice (EAP400 group). (E) EAP $(200 \mathrm{mg} / \mathrm{kg})$-administered and DEXA-treated experimental mice (EAP200 group). (F) EAP (100 mg/kg)-administered and DEXA-treated experimental mice (EAP100 group). Scale bars=40 $\mu \mathrm{m}$. DEXA, dexamethasone; EAP, extracellular polysaccharides purified from Aureobasidium pullulans SM-2001; iNOS, inducible nitric oxide synthase.

are involved in muscle atrophy: Calpain calcium-dependent signaling, lysosomal proteases (cathepsins), the ubiquitin proteasome pathway and the caspase signaling system (6,68-70). There is a common genetic program involved in muscle proteolysis regardless of its etiology; however, distinct signaling pathways are involved to modulate the system $(6,69,71)$. Oxidative stress is a well-known and important inducer of muscle atrophy in response to disuse and in catabolic muscle cachexia (71). In addition, apoptosis and loss of muscle fibers are also involved in the early phase of muscle atrophy, regardless of etiology $(72,73)$.

Glucocorticoid-induced catabolic muscle atrophy is characterized by a reduction and degradation in protein content, organelles, cytoplasm, fiber diameter, resistance to fatigue and muscle strength $(16,21,23,28,74)$. Glucocorticoids are immunosuppressants that are clinically used to suppress swelling 
and acute inflammation. Millions of people take glucocorticoids as chronic therapy to treat various diseases, including asthma, rheumatoid arthritis, primary or secondary adrenal insufficiency, and organ transplants (23). Common side effects of glucocorticoids include nervousness, insomnia, gastrointestinal upset, immunosuppression, arthralgia, myopathy and edema (75). Glucocorticoids have been in commercial use for $>50$ years (76); however, their prolonged use is associated with myopathy, particularly with prolonged high doses. Long-term glucocorticoid therapy enhances the risk of muscle weakness and myopathy by $50 \%(77,78)$. The characteristic features of myopathy include weakness and muscle atrophy, oxidative stress, mitochondrial dysfunction and insulin resistance. Histological alterations associated with muscle atrophy include loss of myosin filaments in sarcomeres, type II specific atrophy of muscle fibers, preservation of Z-bands and thin filaments, and necrosis (74). Steroid-induced myopathy is not only associated with the use of fluorinated steroids, including triamcinolone, $\beta$-methasone and DEXA, but can also be caused by non-fluorinated steroids, such as hydrocortisone and prednisolone (79). In the present study, the potential beneficial skeletal muscle-preserving effects of EAP were examined in a mouse model of DEXA-induced catabolic muscle atrophy.

All of the intact vehicle control mice exhibited normal body weight gain throughout the experimental period, including during the 10 days of acclimation $(80,81)$. The DEXA-induced decreases in body weight detected in the present study were considered to be related to cachexia, due to the potent catabolic effects of DEXA $(82,83)$. Conversely, the increased body weight detected in mice treated with EAP may be associated with the known immunomodulatory effects of EAP $(45,84)$. Generally, good growth patterns are associated with an enhanced immune system $(85,86)$, which is induced by EAP administration (84). Oxymetholone is a $17 \alpha$-alkylated anabolic-androgenic steroid $(33,34)$, which may inhibit the catabolic cachexia-associated decreases in body weight induced by glucocorticoid treatment (87-89).

Overuse of glucocorticoids can facilitate catabolic muscle atrophy, which is characterized by decreased fiber diameter, and reduced and degraded protein contents $(16,21,23,26,28,74)$. In the present study, decreases in calf thickness were detected 5 days after the initial DEXA treatment in DEXA-treated mice, alongside decreased gastrocnemius muscle thickness, and calf muscle strength and weight at sacrifice, as a result of catabolic muscle atrophy. Conversely, oral administration of 100,200 and $400 \mathrm{mg} / \mathrm{kg}$ EAP, and $50 \mathrm{mg} / \mathrm{kg}$ oxymetholone, inhibited DEXA-induced decreases in calf muscle strength and thickness, and gastrocnemius muscle thickness and weight, thus indicating that oxymetholone and EAP may reverse the DEXA-induced atrophic alterations in calf muscles.

Creatine is a naturally occurring nitrogenous organic acid that assists in the supply of energy to the entire body, particularly muscle cells. Creatine is synthesized in the kidney and liver; however, muscles do not possess the ability to synthesize creatine. Creatine is stored in the muscle, according to a concentration gradient, via a specific active transport mechanism from the plasma (90). Skeletal muscle is a large and relatively constant reservoir of creatine in the body $(91,92)$. Creatine is constantly metabolized to its non-ionic cyclic derivative creatinine, over
$1.7 \%$ of creatine is metabolized per day via non-enzymatic hydrolytic cyclization $(93,94)$. Creatinine rapidly diffuses from the muscle into the plasma and is transferred to the urine, with no uptake into muscles $(90,95)$. Therefore, plasma creatine levels can be used as a serum biochemical indicator for skeletal muscle damage, activity or muscle quantity $(26,96,97)$. In the present study, marked increases in serum creatine levels were verified alongside other DEXA-associated catabolic muscle atrophic alterations; this finding was similar to those of previous studies $(16,26)$. Oral administration of 100, 200 and $400 \mathrm{mg} / \mathrm{kg}$ EAP significantly and dose-dependently limited the DEXA-induced increases in serum creatine levels. Particularly, $400 \mathrm{mg} / \mathrm{kg}$ EAP exhibited favorable inhibitory effects on serum creatine level elevations; these effects were comparable with those of $50 \mathrm{mg} / \mathrm{kg}$ oxymetholone, thus indicating that EAP exerts positive muscle-preserving effects against glucocorticoid-induced atrophy.

The medical significance of $\mathrm{LDH}$ is evident due to its extensive presence in body tissues, including heart muscle and blood cells. CK is an enzyme expressed by various tissues and cell types, which is involved in the conversion of creatine and the consumption of adenosine. Since LDH and CK are released during tissue damage, they are considered markers of common disease and injuries, particularly muscle damage. Plasma activities of CK and LDH have been used commonly as markers of muscle tissue damage $(26,98,99)$. They are also markedly elevated in animals with disused muscle atrophy (100). In a DEXA-induced animal model of catabolic muscle atrophy, marked elevations in serum CK levels were noted; however, serum LDH levels were generally decreased due to reduced physiological activity and skeletal muscle fiber concentration $(24,26,101)$. Significantly elevated serum CK levels, indicating decreases in serum LDH levels and muscle damage, thus signifying reduced muscle activity, were demonstrated in the DEXA control mice in the present study. However, significant and dose-dependent decreases in serum CK and increases in serum LDH levels were detected in 100, 200, and $400 \mathrm{mg} / \mathrm{kg}$ EAP-treated mice; these effects were comparable with those of $50 \mathrm{mg} / \mathrm{kg}$ oxymetholone. In particular, $400 \mathrm{mg} / \mathrm{kg}$ EAP exhibited favorable and potent muscle-preserving effects.

Lipid peroxidation can harm surrounding tissues due to the release of various toxic substances (102), and oxidative stress is a significant inducer of muscle atrophy (71). Inhibition of increased lipid peroxidation protects muscles against atrophic alterations $(57,103,104)$. Nitrotyrosine, which is a product of tyrosine nitration that has been detected in numerous pathological disorders, is known as a marker of iNOS-dependent nitrate stress (105-107). In addition, it has been demonstrated to damage antioxidant defense systems in muscle tissues; this was associated with glucocorticoid-induced catabolic muscle atrophic alterations $(26,71,108)$. In the present study, EAP dose-dependently protected the gastrocnemius muscle against DEXA-triggered oxidative stress, reduced DEXA-induced increases in lipid peroxidation and ROS formation, increased DEXA-induced decreases in CAT and SOD activities and GSH contents, and reduced DEXA-induced increases in nitrotyrosine and 4-HNE-immunolabelled muscle fibers. Oxymetholone also exerted strong antioxidative effects against DEXA-induced depletion of antioxidant defense systems, consistent with other studies on anabolic steroids $(109,110)$ and 
previous results in glucocorticoid-induced catabolic muscle atrophic mice (26).

Apoptosis and muscle fiber damage are associated with the early phase of muscle atrophy regardless of etiology (72,73), and caspase-3 and PARP serve key roles in apoptosis $(111,112)$. Increases in the number of caspase- 3 and PARP-immunoreactive muscle fibers in muscle bundles indicate apoptosis and related damage $(26,113,114)$. Furthermore, treatment with glucocorticoids has been reported to induce marked apoptosis in muscles $(23,26)$. Therefore, EAP-induced dose-dependent inhibition of caspase-3 and PARP immunoreactivity in DEXA-treated gastrocnemius muscle bundles may provide direct evidence that EAP can preserve muscle mass through inhibitory effects against DEXA-induced muscle fiber apoptosis.

Muscle structure and mass are evaluated by the equilibrium between protein synthesis and degradation (70). Protein degradation, which is responsible for muscle wasting, is triggered by ATP-ubiquitin-dependent proteolysis (9). A previous study reported that the muscle-specific E3 ubiquitin ligases, including MuRF1 and atrogin-1, are important for muscle atrophy (6). In addition, it has been revealed that the expression levels of MuRF1 and atrogin-1 are increased in atrophic skeletal muscles, and mice deficient in MuRF1 or atrogin-1 are resistant to muscle atrophy $(5,115,116)$. In addition, marked increases in the mRNA expression levels of MuRF1 and atrogin-1 have been observed in glucocorticoid-induced catabolic atrophic muscles $(16,26,28)$. In the present study, marked elevations in the mRNA expression levels of MuRF1 and atrogin-1 in gastrocnemius muscles were detected in the DEXA control group compared with in the intact vehicle control group; however, these elevations were dose-dependently inhibited following treatment with EAP, providing direct evidence to suggest that EAP exerts muscle-protective effects apparently mediated through downregulation of atrogin-1 and MuRF1. In particular, $400 \mathrm{mg} / \mathrm{kg}$ EAP exhibited favorable inhibitory effects on muscle atrogin-1 and MuRF1 mRNA expression; these effects were comparable with those of oxymetholone.

Protein synthesis is activated by the insulin-like growth factor 1 (IGF-1)/PI3K/Akt pathway $(6,70)$. PI3K, which is initiated by IGF or insulin, in turn activates the serine/threonine kinase Akt (69). Marked downregulation of PI3K and Akt1 mRNA expression were detected in DEXA-treated mice with catabolic muscle atrophic alterations; this finding was consistent with the results of a previous study (26). Conversely, EAP dose-dependently upregulated the mRNA expression levels of Akt1 and PI3K compared with in the DEXA control group, which indicated that EAP may resist glucocorticoid-induced muscle atrophy and activate muscle protein synthesis; these effects were comparable with those of oxymetholone. Notably, $400 \mathrm{mg} / \mathrm{kg}$ EAP exhibited favorable upregulating effects on Akt1 and PI3K mRNA expression, comparable with those of oxymetholone.

Adenosine modulates numerous physiological functions in various tissues, including skeletal muscle and the cardiovascular system (117-119). Adenosine is considered to be involved in the synergistic effects of contraction- and insulin-stimulated glucose uptake in skeletal muscle, and in the regulation of blood flow to skeletal muscle $(120,121)$. Specific adenosine receptors are associated with facilitation of the physiological effects of adenosine (122). TRPV4 is a member of the TRP channel superfamily $(123,124)$, which serves an osmosensory or mechanosensory role in numerous musculoskeletal tissues, and prevents muscle atrophy and bone loss $(124,125)$. Subcutaneous treatment with DEXA significantly decreased the mRNA expression levels of TRPV4 and A1R in gastrocnemius muscle, which may be associated with catabolic muscle atrophy-related proteolysis; these findings were similar to those of a previous study (26). EAP dose-dependently upregulated A1R and TRPV4 mRNA expression compared with in the DEXA control group, providing direct evidence that $400 \mathrm{mg} / \mathrm{kg}$ EAP can increase muscle growth and resist DEXA-induced catabolic muscle atrophy; these effects were comparable with those of $50 \mathrm{mg} / \mathrm{kg}$ oxymetholone.

Myostatin is a secreted growth differentiation factor that inhibits growth and muscle differentiation in myogenesis. It is a powerful negative controller of muscle growth $(9,16)$. The sirtuin protein family (SIRT1-7) possesses ADP ribosyltransferase activity and/or NAD ${ }^{+}$-dependent deacetylase activity (126). SIRT1 controls numerous biological processes, including differentiation, cell proliferation, metabolism and apoptosis (127). In addition, it regulates transcription of peroxisome proliferator-activated receptor- $\gamma$ co-activator $1 \alpha$ in skeletal muscle (128) and inhibits muscle regeneration, which causes cachexia (129). In catabolic muscle atrophy, the mRNA expression levels of SIRT1 and myostatin have been detected alongside decreases in muscle mass $(16,25,26,130)$; similar findings were induced with DEXA treatment in the present study. However, elevations in the expression levels of SIRT1, a representative inhibitor of muscle regeneration, and myostatin, a strong negative regulator of muscle growth, were dose-dependently inhibited by treatment with EAP. In addition, EAP dose-dependently inhibited increases in myostatin-immunoreactive fibers, as determined by immunohistochemical analysis, providing evidence of muscle-shielding effects via downregulation of SIRT1 and myostatin. Notably, $400 \mathrm{mg} / \mathrm{kg}$ EAP exhibited favorable inhibitory effects on muscle myostatin and SIRT1 mRNA expression, and myostatin immunoreactivity in muscle fibers; these effects were comparable with those of $50 \mathrm{mg} / \mathrm{kg}$ oxymetholone.

Glucocorticoid-induced catabolic muscle atrophic alterations have been reported to induce marked histopathological alterations, including microvacuolation, diminished muscle fiber diameter, fibrosis and collagen deposition, as well protein degradation $(15,21,26)$; these alterations were observed in the present study. However, in the present study, muscle atrophy-associated alterations were reduced by treatment with oxymetholone or EAP. These findings suggested that oxymetholone or EAP may protect muscles against DEXA-induced catabolic atrophy. EAP exhibited favorable inhibitory effects on histopathological muscle fibrosis and atrophic alterations, which were compared with the effects of oxymetholone.

In conclusion, EAP exerted favorable ameliorating effects on DEXA-induced catabolic muscle atrophy via anti-inflammatory and antioxidant effects, which were mediated by modulation of the expression of genes associated with muscle protein synthesis (Akt1, PI3K, A1R and TRPV4) and degradation (atrogin-1, MuRF1, myostatin and SIRT1). Therefore, EAP may be helpful in improving various muscle atrophy conditions with 
various etiologies. Notably, $400 \mathrm{mg} / \mathrm{kg}$ EAP exhibited favorable muscle-protective effects against DEXA-induced catabolic muscle atrophy, which were comparable with the effects of $50 \mathrm{mg} / \mathrm{kg}$ oxymetholone.

\section{Acknowledgements}

The present study was financially supported by the Ministry of Trade, Industry, and Energy, Korea, under the 'Regional Specialized Industry Development Program' (grant no. R0005069; Development of functional food products for improving the locomotive syndrome using black yeast $\beta$-glucan) supervised by the Korea Institute for Advancement of Technology.

\section{References}

1. Brooks SV and Faulkner JA: Skeletal muscle weakness in old age: Underlying mechanisms. Med Sci Sports Exerc 26: 432-439, 1994.

2. Frontera WR, Hughes VA, Fielding RA, Fiatarone MA, Evans WJ and Roubenoff R: Aging of skeletal muscle: A 12-yr longitudinal study. J Appl Physiol 88: 1321-1326, 2000.

3. Metter EJ, Talbot LA, Schrager M and Conwit R: Skeletal muscle strength as a predictor of all-cause mortality in healthy men. J Gerontol A Biol Sci Med Sci 57: B359-B365, 2002.

4. Glass DJ: Molecular mechanisms modulating muscle mass. Trends Mol Med 9: 344-350, 2003.

5. Bodine SC, Latres E, Baumhueter S, Lai VK, Nunez L, Clarke BA, Poueymirou WT, Panaro FJ, Na E, Dharmarajan K, et al: Identification of ubiquitin ligases required for skeletal muscle atrophy. Science 294: 1704-1708, 2001.

6. Glass DJ: Skeletal muscle hypertrophy and atrophy signaling pathways. Int J Biochem Cell Biol 37: 1974-1984, 2005.

7. Ramírez C, Russo TL, Sandoval MC, Dentillo AA, Couto MA, Durigan JL and Salvini TF: Joint inflammation alters gene and protein expression and leads to atrophy in the tibialis anterior muscle in rats. Am J Phys Med Rehabil 90: 930-939, 2011

8. Hofer T, Marzetti E, Xu J, Seo AY, Gulec S, Knutson MD, Leeuwenburgh $C$ and Dupont-Versteegden EE: Increased iron content and RNA oxidative damage in skeletal muscle with aging and disuse atrophy. Exp Gerontol 43: 563-570, 2008.

9. Onda A, Jiao Q, Nagano Y, Akimoto T, Miyamoto T, Minamisawa S and Fukubayashi T: Acupuncture ameliorated skeletal muscle atrophy induced by hindlimb suspension in mice. Biochem Biophys Res Commun 410: 434-439, 2011.

10. Booth FW: Physiologic and biochemical effects of immobilization on muscle. Clin Orthop Relat Res 219: 15-20, 1987.

11. Thomas DR: Loss of skeletal muscle mass in aging: Examining the relationship of starvation, sarcopenia and cachexia. Clin Nutr 26: 389-399, 2007.

12. Léger B, Senese R, Al-Khodairy AW, Dériaz O, Gobelet C, Giacobino JP and Russell AP: Atrogin-1, MuRF1, and FoXO, as well as phosphorylated GSK-3beta and 4E-BP1 are reduced in skeletal muscle of chronic spinal cord-injured patients. Muscle Nerve 40: 69-78, 2009

13. Kawano F, Tanihata J, Sato S, Nomura S, Shiraishi A, Tachiyashiki K and Imaizumi K: Effects of dexamethasone on the expression of beta(1)-, beta (2)- and beta (3)-adrenoceptor mRNAs in skeletal and left ventricle muscles in rats. J Physiol Sci 59: 383-390, 2009.

14. Dardevet D, Sornet C, Savary I, Debras E, Patureau-Mirand P and Grizard J: Glucocorticoid effects on insulin- and IGF-I-regulated muscle protein metabolism during aging. J Endocrinol 156: 83-89, 1998.

15. Kanda F, Takatani K, Okuda S, Matsushita T and Chihara K: Preventive effects of insulinlike growth factor-I on steroid-induced muscle atrophy. Muscle Nerve 22: 213-217, 1999.

16. Gilson H, Schakman O, Combaret L, Lause P, Grobet L, Attaix D, Ketelslegers JM and Thissen JP: Myostatin gene deletion prevents glucocorticoid-induced muscle atrophy. Endocrinology 148: 452-460, 2007.

17. Auclair D, Garrel DR, Chaouki Zerouala A and Ferland LH: Activation of the ubiquitin pathway in rat skeletal muscle by catabolic doses of glucocorticoids. Am J Physiol 272: C1007-C1016, 1997.
18. Hasselgren PO: Glucocorticoids and muscle catabolism. Curr Opin Clin Nutr Metab Care 2: 201-205, 1999.

19. Komamura K, Shirotani-Ikejima H, Tatsumi R, Tsujita-Kuroda Y, Kitakaze M, Miyatake K, Sunagawa K and Miyata T: Differential gene expression in the rat skeletal and heart muscle in glucocorticoid-induced myopathy: Analysis by microarray. Cardiovasc Drugs Ther 17: 303-310, 2003.

20. McPherron AC, Lawler AM and Lee SJ: Regulation of skeletal muscle mass in mice by a new TGF- $\beta$ superfamily member. Nature 387: 83-90, 1997.

21. Qin J, Du R, Yang YQ, Zhang HQ, Li Q, Liu L, Guan H, Hou J and An XR: Dexamethasone-induced skeletal muscle atrophy was associated with upregulation of myostatin promoter activity. Res Vet Sci 94: 84-89, 2013.

22. Allen DL, Bandstra ER, Harrison BC, Thorng S, Stodieck LS, Kostenuik PJ, Morony S, Lacey DL, Hammond TG, Leinwand LL, et al: Effects of spaceflight on murine skeletal muscle gene expression. J Appl Physiol 1985 106: 582-595, 2009.

23. Dirks-Naylor AJ and Griffiths CL: Glucocorticoid-induced apoptosis and cellular mechanisms of myopathy. J Steroid Biochem Mol Biol 117: 1-7, 2009.

24. Orzechowski A, Ostaszewski P, Wilczak J, Jank M, Bałasińska B, Wareski P and Fuller J Jr: Rats with a glucocorticoid-induced catabolic state show symptoms of oxidative stress and spleen atrophy: The effects of age and recovery. J Vet Med A Physiol Pathol Clin Med 49: 256-263, 2002.

25. Alamdari N, Aversa Z, Castillero E, Gurav A, Petkova V, Tizio S and Hasselgren PO: Resveratrol prevents dexamethasone-induced expression of the muscle atrophy-related ubiquitin ligases atrogin-1 and MuRF1 in cultured myotubes through a SIRT1-dependent mechanism. Biochem Biophys Res Commun 417: 528-533, 2012.

26. Kim JW, Ku SK, Han MH, Kim KY, Kim SG, Kim GY, Hwang HJ, Kim BW, Kim CM and Choi YH: The administration of Fructus Schisandrae attenuates dexamethasone-induced muscle atrophy in mice. Int J Mol Med 36: 29-42, 2015a.

27. Benveniste O, Jacobson L, Farrugia ME, Clover L and Vincent A: MuSK antibody positive myasthenia gravis plasma modifies MURF-1 expression in C2C12 cultures and mouse muscle in vivo. J Neuroimmunol 170: 41-48, 2005.

28. Jones A, Hwang DJ, Narayanan R, Miller DD and Dalton JT: Effects of a novel selective androgen receptor modulator on dexamethasone-induced and hypogonadism-induced muscle atrophy. Endocrinology 151: 3706-3719, 2010.

29. Yang Z, Nakagawa K, Sarkar A, Maruyama J, Iwasa H, Bao Y, Ishigami-Yuasa M, Ito S, Kagechika H, Hata S, et al: Screening with a novel cell-based assay for TAZ activators identifies a compound that enhances myogenesis in $\mathrm{C} 2 \mathrm{C} 12$ cells and facilitates muscle repair in a muscle injury model. Mol Cell Biol 34: 1607-1621, 2014.

30. Ringold HJ, Batres E, Halpern O and Necoechea E: Steroids. CV. ${ }^{1}$ 2-Methyl and 2-hydroxymethylene-androstane derivatives. J Am Chem Soc 81: 427-432, 1959.

31. Lennon HD: Effects of various 17-alpha-alkyl substitutions and structural modifications of steroids on sulfobromophthalein (BSP) retention in rabbits. Steroids 7: 157-170, 1966.

32. Dorfman RI and Kincl FA: Relative potency of steroids in an anabolic-androgenic assay using the castrated rat. Endocrinology 72: 259-266, 1963

33. Pavlatos AM, Fultz O, Monberg MJ and Vootkur A: Review of oxymetholone: A 17alpha-alkylated anabolic-androgenic steroid. Clin Ther 23: 789-801, discussion 771, 2001.

34. Isaacs J, Loveland K, Mallu S, Adams S and Wodicka R: The use of anabolic steroids as a strategy in reversing denervation atrophy after delayed nerve repair. Hand (NY) 6: 142-148, 2011.

35. Kim JW, Ku SK, Kim KY, Kim SG, Han MH, Kim GY, Hwang HJ, Kim BW, Kim CM and Choi YH: Schisandrae Fructus supplementation ameliorates sciatic neurectomy-induced muscle atrophy in mice. Oxid Med Cell Longev 2015: 872428, 2015.

36. Young GP, Bhathal PS, Sullivan JR, Wall AJ, Fone DJ and Hurley TH: Fatal hepatic coma complicating oxymetholone therapy in multiple myeloma. Aust N Z J Med 7: 47-51, 1977.

37. Wood P and Yin JA: Oxymetholone hepatotoxicity enhanced by concomitant use of cyclosporin $\mathrm{A}$ in a bone marrow transplant patient. Clin Lab Haematol 16: 201-204, 1994.

38. Walker ID, Davidson JF, Young P and Conkie JA: Plasma fibrinolytic activity following oral anabolic steroid therapy. Thromb Diath Haemorrh 34: 236-245, 1975.

39. Tzianabos AO: Polysaccharide immunomodulators as therapeutic agents: Structural aspects and biologic function. Clin Microbiol Rev 13: 523-533, 2000. 
40. Estrada A, Yun CH, Van Kessel A, Li B, Hauta S and Laarveld B Immunomodulatory activities of oat beta-glucan in vitro and in vivo. Microbiol Immunol 41: 991-998, 1997.

41. Lotzová E and Gutterman JU: Effect of glucan on natural killer (NK) cells: Further comparison between NK cell and bone marrow effector cell activities. J Immunol 123: 607-611, 1979.

42. Hofer M and Pospísil M: Glucan as stimulator of hematopoiesis in normal and gamma-irradiated mice. A survey of the authors results. Int J Immunopharmacol 19: 607-609, 1997.

43. Lee JN, Lee DY, Ji IH, Kim GE, Kim HN, Sohn J, Kim S and Kim CW: Purification of soluble beta-glucan with immune-enhancing activity from the cell wall of yeast. Biosci Biotechnol Biochem 65: 837-841, 2001

44. Benach JL, Habicht GS, Holbrook TW and Cook JA: Glucan as an adjuvant for a murine Babesia microti immunization trial. Infect Immun 35: 947-951, 1982

45. Yoon HS, Kim JW, Cho HR, Moon SB, Shin HD, Yang KJ, Lee HS, Kwon YS and Ku SK: Immunomodulatory effects of Aureobasidium pullulans SM-2001 exopolymers on the cyclophosphamide-treated mice. J Microbiol Biotechnol 20: 438-445, 2010.

46. Jung MY, Kim JW, Kim KY, Choi SH and Ku SK: Polycan, a $\beta$-glucan from Aureobasidium pullulans SM-2001, mitigates ovariectomy-induced osteoporosis in rats. Exp Ther Med 12 1251-1262, 2016.

47. Kim HD, Cho HR, Moon SB, Shin HD, Yang KJ, Park BR, Jang HJ, Kim LS, Lee HS and Ku SK: Effects of $\beta$-glucan from Aureobasidium pullulans on acute inflammation in mice. Arch Pharm Res 30: 323-328, 2007.

48. Kim HD, Cho HR, Moon SB, Shin HD, Yang KJ, Park BR, Jang HJ, Kim LS, Lee HS and Ku SK: Effect of Exopolymers from Aureobasidum pullulans on formalin-induced chronic paw inflammation in mice. J Microbiol Biotechnol 16: 1954-1960, 2006.

49. Ku SK, Lee YJ, Lee SD, Cho HR, Moon SB, Kim KY, Kwon YS and Kim JW: Nephroprotective effect of Polycan on acute renal failure induced by cisplatin in rats. ISRN Vet Sci 2012: 862104, 2012.

50. Ku SK, Kim JW, Cho HR, Kim KY, Min YH, Park JH, Kim JS Park JH, Seo BI and Roh SS: Effect of $\beta$-glucan originated from Aureobasidium pullulans on asthma induced by ovalbumin in mouse. Arch Pharm Res 35: 1073-1081, 2012a.

51. Kim JW, Cho HR and Ku SK: Efficacy test of Polycan, a beta-glucan originated from Aureobasidium pullulans SM-2001, on anterior cruciate ligament transection and partial medial meniscectomy-induced-osteoarthritis rats. J Microbiol Biotechnol 22: 274-282, 2012a.

52. Kim YS, Kang SJ, Kim JW, Cho HR, Moon SB, Kim KY, Lee HS, Han CH, Ku SK and Lee YJ: Effects of Polycan, a $\beta$-glucan, on experimental periodontitis and alveolar bone loss in Sprague-Dawley rats. J Periodontal Res 47: 800-810, $2012 \mathrm{~b}$

53. Seo HP, Kim JM, Shin HD, Kim TK, Chang HJ, Park BR and Lee JW: Production of $\beta-1,3 / 1,6$-glucan by Aureobasidium pullulans SM-2001. Korean J Bitechnol Bioeng 17: 376-380, 2002.

54. Del Rio D, Stewart AJ and Pellegrini N: A review of recent studies on malondialdehyde as toxic molecule and biological marker of oxidative stress. Nutr Metab Cardiovasc Dis 15: 316-328, 2005.

55. Jamall IS and Smith JC: Effects of cadmium on glutathione peroxidase, superoxide dismutase, and lipid peroxidation in the rat heart: A possible mechanism of cadmium cardiotoxicity. Toxicol Appl Pharmacol 80: 33-42, 1985.

56. Lowry OH, Rosebrough NJ, Farr AL and Randall RJ: Protein measurement with the Folin phenol reagent. J Biol Chem 193 265-275, 1951.

57. He HJ, Wang GY, Gao Y, Ling WH, Yu ZW and Jin TR: Curcumin attenuates Nrf2 signaling defect, oxidative stress in muscle and glucose intolerance in high fat diet-fed mice. World J Diabetes 3: 94-104, 2012.

58. Sedlak J and Lindsay RH: Estimation of total, protein-bound, and nonprotein sulfhydryl groups in tissue with Ellman's reagent. Anal Biochem 25: 192-205, 1968.

59. Aebi H: Catalase. In: Methods in Enzymatic Analysis. Bergmeyer HU (ed). Academic Press, New York, NY, pp673-686, 1974.

60. Sun Y, Oberley LW and Li Y: A simple method for clinical assay of superoxide dismutase. Clin Chem 34: 497-500, 1988.

61. Yokoyama U, Minamisawa S, Quan H, Akaike T, Suzuki S, Jin M, Jiao Q, Watanabe M, Otsu K, Iwasaki S, et al: Prostaglandin E2-activated Epac promotes neointimal formation of the rat ductus arteriosus by a process distinct from that of cAMP-dependent protein kinase A. J Biol Chem 283: 28702-28709, 2008
62. Livak KJ and Schmittgen TD: Analysis of relative gene expression data using real-time quantitative PCR and the the $2^{-\Delta \Delta \mathrm{Ct}}$ method. Methods 25: 402-408, 2001.

63. Ogawa T, Nikawa T, Furochi H, Kosyoji M, Hirasaka K, Suzue N, Sairyo K, Nakano S, Yamaoka T, Itakura M, et al: Osteoactivin upregulates expression of MMP-3 and MMP-9 in fibroblasts infiltrated into denervated skeletal muscle in mice. Am J Physiol Cell Physiol 289: C697-C707, 2005.

64. Tipoe GL, Leung TM, Liong EC, Lau TY, Fung ML and Nanji AA: Epigallocatechin-3-gallate (EGCG) reduces liver inflammation, oxidative stress and fibrosis in carbon tetrachloride (CCl4)-induced liver injury in mice. Toxicology 273: 45-52, 2010.

65. Shi SR, Chaiwun B, Young L, Cote RJ and Taylor CR: Antigen retrieval technique utilizing citrate buffer or urea solution for immunohistochemical demonstration of androgen receptor in formalin-fixed paraffin sections. J Histochem Cytochem 41: 1599-1604, 1993.

66. Levene A: Pathological factors influencing excision of tumours in the head and neck. Part I. Clin Otolaryngol Allied Sci 6: 145-151, 1981.

67. Ludbrook J: Update: Microcomputer statistics packages. A personal view. Clin Exp Pharmacol Physiol 24: 294-296, 1997.

68. Jackman RW and Kandarian SC: The molecular basis of skeletal muscle atrophy. Am J Physiol Cell Physiol 287: C834-C843, 2004.

69. Sandri M: Signaling in muscle atrophy and hypertrophy. Physiology (Bethesda) 23: 160-170, 2008.

70. Glass DJ: Signaling pathways perturbing muscle mass. Curr Opin Clin Nutr Metab Care 13: 225-229, 2010.

71. Powers SK, Kavazis AN and McClung JM: Oxidative stress and disuse muscle atrophy. J Appl Physiol 1985 102: 2389-2397, 2007.

72. Arakawa T, Katada A, Shigyo H, Kishibe K, Adachi M, Nonaka S and Harabuchi Y: Electrical stimulation prevents apoptosis in denervated skeletal muscle. NeuroRehabilitation 27: 147-154, 2010.

73. Lim JY and Han TR: Effect of electromyostimulation on apoptosis-related factors in denervation and reinnervation of rat skeletal muscles. Muscle Nerve 42: 422-430, 2010.

74. Mastagllia FL: Drug induced myopathies. Pract Neurol 6: $4-13,2006$

75. Seale JP and Compton MR: Side-effects of corticosteroid agents. Med J Aust 144: 139-142, 1986.

76. Zoorob RJ and Cender D: A different look at corticosteroids Am Fam Physician 58: 443-450, 1998.

77. Bowyer SL, LaMothe MP and Hollister JR: Steroid myopathy: Incidence and detection in a population with asthma. J Allergy Clin Immunol 76: 234-242, 1985

78. Covar RA, Leung DY, McCormick D, Steelman J, Zeitler P and Spahn JD: Risk factors associated with glucocorticoid-induced adverse effects in children with severe asthma. J Allergy Clin Immunol 106: 651-659, 2000.

79. Owczarek J, Jasińska M and Orszulak-Michalak D: Drug-induced myopathies. An overview of the possible mechanisms. Pharmacol Rep 57: 23-34, 2005.

80. Fox JG, Cohen BJ and Loew FM: Laboratory animal medicine. Academic Press Inc., Orlando, Fl, 1984

81. Tajima Y: Biological reference data book on experimental animals. Soft Science Inc., Tokyo, 1989.

82. Gupta AK and Chow M: Prednicarbate (Dermatop): Profile of a corticosteroid. J Cutan Med Surg 8: 244-247, 2004.

83. Cho YH, Chung IK, Cheon WH, Lee HS and Ku SK: Effect of DHU001, a polyherbal formula on formalin-induced paw chronic inflammation of mice. Toxicol Res 27: 95-102, 2011.

84. Lee HS, Yang KJ, Shin HD, Park BR, Son CW, Jang HJ, Park DC, Jung YM and Ku SK: Single oral dose toxicity studies of Polycan, $\beta$-glucan originated from Aureobasidium in mice. Toxicol Res 21: 361-365, 2005.

85. Duarte CG, dos Santos GL, Azzolini AE and de Assis Pandochi AI: The effect of the antithyroid drug propylthiouracil on the alternative pathway of complement in rats. Int J Immunopharmacol 22: 25-33, 2000

86. Pinzone JJ, Fox ML, Sastry MK, Parenti DM and Simon GL: Plasma leptin concentration increases early during highly active antiretroviral therapy for acquired immunodeficiency syndrome, independent of body weight. J Endocrinol Invest 28: RC1-RC3, 2005. 
87.Hengge UR, Baumann M, Maleba R, Brockmeyer NH and Goos M: Oxymetholone promotes weight gain in patients with advanced human immunodeficiency virus (HIV-1) infection. Br J Nutr 75: 129-138, 1996.

88.Hengge UR, Stocks K, Faulkner S, Wiehler H, Lorenz C, Jentzen W, Hengge D and Ringham G: Oxymetholone for the treatment of HIV-wasting: A double-blind, randomized, placebo-controlled phase III trial in eugonadal men and women. HIV Clin Trials 4: 150-163, 2003.

89. Hengge UR, Stocks K, Wiehler H, Faulkner S, Esser S, Lorenz C, Jentzen W, Hengge D, Goos M, Dudley RE, et al: Double-blind, randomized, placebo-controlled phase III trial of oxymetholone for the treatment of HIV wasting. AIDS 17: 699-710, 2003.

90.Wyss $\mathrm{M}$ and Kaddurah-Daouk R: Creatine and creatinine metabolism. Physiol Rev 80: 1107-1213, 2000.

91.Hunter A (ed): The biological distribution of creatine and creatinine. In: Creatine and Creatinine. Longmans, Green, London, pp73-113, 1928.

92. Balsom PD, Söderlund K and Ekblom B: Creatine in humans with special reference to creatine supplementation. Sports Med 18: 268-280, 1994.

93. Fitch CD, Lucy DD, Bornhofen JH and Dalrymple GV: Creatine metabolism in skeletal muscle. II. Creatine kinetics in man. Neurology 18: 32-42, 1968.

94. Bloch K and Schoenheimer R: Studies in protein metabolism. XI. The metabolic relation of creatine and creatinine studies with isotopic nitrogen. J Biol Chem 131: 111-119, 1939.

95.Heymsfield SB, Arteaga C, McManus C, Smith J and Moffitt S: Measurement of muscle mass in humans: Validity of the 24-hour urinary creatinine method. Am J Clin Nutr 37: 478-494, 1983

96.Sala A, Tarnopolsky M, Webber C, Norman G and Barr R: Serum creatinine: A surrogate measurement of lean body mass in children with acute lymphoblastic leukemia. Pediatr Blood Cancer 45: 16-19, 2005.

97.Stimpson SA, Turner SM, Clifton LG, Poole JC, Mohammed HA, Shearer TW, Waitt GM, Hagerty LL, Remlinger KS, Hellerstein MK, et al: Total-body creatine pool size and skeletal muscle mass determination by creatine-(methyl-D3) dilution in rats. J Appl Physiol 1985 112: 1940-1948, 2012

98.Zhang Y, Huang JJ, Wang ZQ, Wang N and Wu ZY: Value of muscle enzyme measurement in evaluating different neuromuscular diseases. Clin Chim Acta 413: 520-524, 2012.

99. Choi M, Park H, Cho S and Lee M: Vitamin D3 supplementation modulates inflammatory responses from the muscle damage induced by high-intensity exercise in SD rats Cytokine 63: 27-35, 2013.

100. Cohen I, Bogin E, Chechick A and Rzetelny V: Biochemical alterations secondary to disuse atrophy in the rat's serum and limb tissues. Arch Orthop Trauma Surg 119: 410-417, 1999.

101.Pellegrino MA, D'Antona G, Bortolotto S, Boschi F, Pastoris O, Bottinelli R, Polla B and Reggiani C: Clenbuterol antagonizes glucocorticoid-induced atrophy and fibre type transformation in mice. Exp Physiol 89: 89-100, 2004.

102.Comporti M: Lipid peroxidation and cellular damage in toxic liver injury. Lab Invest 53: 599-623, 1985.

103. Gore M, Fiebig R, Hollander J, Leeuwenburgh C, Ohno H and Ji LL: Endurance training alters antioxidant enzyme gene expression in rat skeletal muscle. Can J Physiol Pharmacol 76: $1139-1145,1998$

104. Süleyman H, Cadirci E, Albayrak A, Polat B, Halici Z, Koc F, Hacimuftuoglu A and Bayir Y: Comparative study on the gastroprotective potential of some antidepressants in indomethacin-induced ulcer in rats. Chem Biol Interact 180 : 318-324, 2009.

105. Chen JH, Tipoe GL, Liong EC, So HS, Leung KM, Tom WM Fung PC and Nanji AA: Green tea polyphenols prevent toxin-induced hepatotoxicity in mice by down-regulating inducible nitric oxide-derived prooxidants. Am J Clin Nutr 80 742-751, 2004

106. Mohiuddin I, Chai H, Lin PH, Lumsden AB, Yao Q and Chen C: Nitrotyrosine and chlorotyrosine: Clinical significance and biological functions in the vascular system. J Surg Res 133: 143-149, 2006.

107. Pacher P, Beckman JS and Liaudet L: Nitric oxide and peroxynitrite in health and disease. Physiol Rev 87: 315-424, 2007.

108. Salvini TF, Durigan JL, Peviani SM and Russo TL: Effects of electrical stimulation and stretching on the adaptation of denervated skeletal muscle: Implications for physical therapy. Rev Bras Fisioter 16: 175-183, 2012.
109. Delgado J, Saborido A and Megías A: Prolonged treatment with the anabolic-androgenic steroid stanozolol increases antioxidant defences in rat skeletal muscle. J Physiol Biochem 66: 63-71, 2010.

110. Yoo YE and Ko CP: Dihydrotestosterone ameliorates degeneration in muscle, axons and motoneurons and improves motor function in amyotrophic lateral sclerosis model mice. PLoS One 7: e37258, 2012

111. Nuñez G, Benedict MA, Hu Y and Inohara N: Caspases: The proteases of the apoptotic pathway. Oncogene 17: 3237-3245, 1998.

112. Barrett KL, Willingham JM, Garvin AJ and Willingham MC: Advances in cytochemical methods for detection of apoptosis. J Histochem Cytochem 49: 821-832, 2001.

113. Dam AD, Mitchell AS, Rush JW and Quadrilatero J: Elevated skeletal muscle apoptotic signaling following glutathione depletion. Apoptosis 17: 48-60, 2012.

114. Yen YP, Tsai KS, Chen YW, Huang CF, Yang RS and Liu SH: Arsenic induces apoptosis in myoblasts through a reactive oxygen species-induced endoplasmic reticulum stress and mitochondrial dysfunction pathway. Arch Toxicol 86: 923-933, 2012.

115. Gomes MD, Lecker SH, Jagoe RT, Navon A and Goldberg AL: Atrogin-1, a muscle-specific F-box protein highly expressed during muscle atrophy. Proc Natl Acad Sci USA 98: 14440-14445, 2001.

116. Cohen S, Brault JJ, Gygi SP, Glass DJ, Valenzuela DM, Gartner C, Latres E and Goldberg AL: During muscle atrophy, thick, but not thin, filament components are degraded by MuRF1-dependent ubiquitylation. J Cell Biol 185: 1083-1095, 2009.

117. Berne RM, Knabb RM, Ely SW and Rubio R: Adenosine in the local regulation of blood flow: A brief overview. Fed Proc 42: 3136-3142, 1983.

118. Segal SS and Kurjiaka DT: Coordination of blood flow control in the resistance vasculature of skeletal muscle. Med Sci Sports Exerc 27: 1158-1164, 1995 .

119. Hespel P and Richter EA: Role of adenosine in regulation of carbohydrate metabolism in contracting muscle. In: Skeletal Muscle Metabolism in Exercise and Diabetes. Richter EA, Kiens B, Galbo H and Saltin B (eds). Plenum Press, New York, NY, pp97-106, 1998.

120.Dobson JG Jr, Rubio R and Berne RM: Role of adenine nucleotides, adenosine, and inorganic phosphate in the regulation of skeletal muscle blood flow. Circ Res 29: 375-384, 1971.

121. Vergauwen L, Hespel P and Richter EA: Adenosine receptors mediate synergistic stimulation of glucose uptake and transport by insulin and by contractions in rat skeletal muscle. J Clin Invest 93: 974-981, 1994

122. Lynge J and Hellsten Y: Distribution of adenosine A1, A2A and A2B receptors in human skeletal muscle. Acta Physiol Scand 169: 283-290, 2000

123. Caterina MJ, Schumacher MA, Tominaga M, Rosen TA, Levine JD and Julius D: The capsaicin receptor: A heat-activated ion channel in the pain pathway. Nature 389: 816-824, 1997.

124. Guilak F, Leddy HA and Liedtke W: Transient receptor potential vanilloid 4: The sixth sense of the musculoskeletal system? Ann N Y Acad Sci 1192: 404-409, 2010.

125. Mizoguchi F, Mizuno A, Hayata T, Nakashima K, Heller S, Ushida T, Sokabe M, Miyasaka N, Suzuki M, Ezura Y, et al: Transient receptor potential vanilloid 4 deficiency suppresses unloading-induced bone loss. J Cell Physiol 216: 47-53, 2008.

126. Michishita E, Park JY, Burneskis JM, Barrett JC and Horikawa I: Evolutionarily conserved and nonconserved cellular localizations and functions of human SIRT proteins. Mol Biol Cell 16: 4623-4635, 2005.

127. Haigis MC and Guarente LP: Mammalian sirtuins - emerging roles in physiology, aging, and calorie restriction. Genes Dev 20: 2913-2921, 2006

128. Amat R, Planavila A, Chen SL, Iglesias R, Giralt M and Villarroya F: SIRT1 controls the transcription of the peroxisome proliferator-activated receptor-gamma Co-activator-1alpha (PGC-1alpha) gene in skeletal muscle through the PGC-1alpha autoregulatory loop and interaction with MyoD. J Biol Chem 284: 21872-21880, 2009.

129. Toledo M, Busquets S, Ametller E, López-Soriano FJ and Argilés JM: Sirtuin 1 in skeletal muscle of cachectic tumour-bearing rats: A role in impaired regeneration? J Cachexia Sarcopenia Muscle 2: 57-62, 2011.

130. Amat R, Solanes G, Giralt M and Villarroya F: SIRT1 is involved in glucocorticoid-mediated control of uncoupling protein-3 gene transcription. J Biol Chem 282: 34066-34076, 2007.

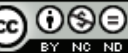

This work is licensed under a Creative Commons Attribution-NonCommercial-NoDerivatives 4.0 International (CC BY-NC-ND 4.0) License. 